UMR 5824

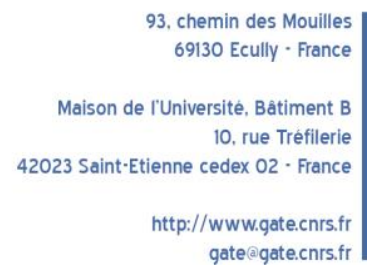

WP 1714 - April 2017, this version November 2017

\title{
Aiming to choose correctly or to choose wisely? The optimality-accuracy trade-off in decisions under uncertainty
}

Thomas Garcia, Sébastien Massoni

\begin{abstract}
:
When making a decision under uncertainty, individuals aim to achieve opti- mality. In general, an accurate decision is optimal. However, in real life situations asymmetric stakes induce an unusual divergence between optimality and accuracy. We highlight this optimality-accuracy trade-off and study its origins using two experiments on perceptual decision making. We use Signal Detection Theory as a normative benchmark. The first experiment confirms the existence of an optimality-accuracy trade-off with a leading role of accuracy. The second experiment explains this trade-off by the concern of people for being right.
\end{abstract}

\section{Keywords:}

Optimality, accuracy, signal detection theory, incentives, experiment

JEL codes:

D8, D83, Y08

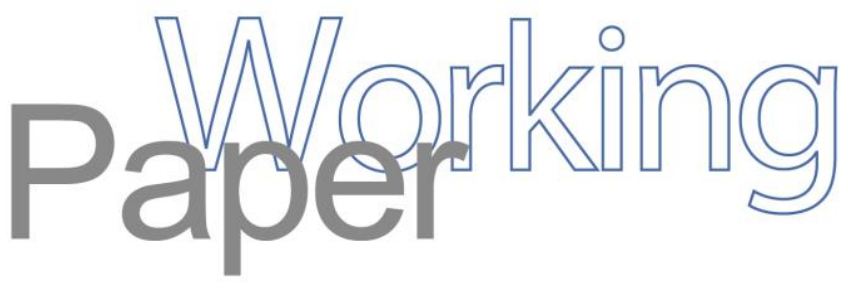




\title{
Aiming to choose correctly or to choose wisely? The optimality-accuracy trade-off in decisions under uncertainty
}

\author{
Thomas Garcia ${ }^{1,2 *}$ and Sébastien Massoni ${ }^{2,3 \dagger}$ \\ ${ }^{1}$ Univ Lyon, Université Lumière Lyon 2, GATE L-SE UMR 5824, \\ F-69130 Ecully, France \\ ${ }^{2}$ QuBE - School of Economics and Finance, QUT, Brisbane, Australia \\ ${ }^{3}$ Australian Centre for Entrepreneurship Research, QUT, Brisbane, Australia
}

\begin{abstract}
When making a decision under uncertainty, individuals aim to make the best choice. In general, the best solution, defined as the optimal solution, is the solution maximizing expected benefits. However, the quality of a decision can also be assessed based on the accuracy of the decision. While most of the time an accurate decision leads to the optimal decision, different types of successes and errors rewarded asymmetrically induce a divergence between accuracy and optimality. In this situation, individuals may face a trade-off between maximizing accuracy and maximizing expected benefits. Using Signal Detection Theory as a normative benchmark, we highlight this optimality-accuracy trade-off and study its origins using two laboratory experiments on perceptual decision-making. The first experiment confirms the existence of the trade-off with a leading role of accuracy. It also gives evidence on the prevalence of a payoff approach over an utility approach to assess
\end{abstract}

*garcia@gate.cnrs.fr

†sebastien.massoni@gmail.com

Acknowledgements: This research was funded by an internal grant from QuBE - QUT. It was performed within the framework of the LABEX CORTEX (ANR-11-LABX-0042) of Université de Lyon, within the program Investissements d'Avenir (ANR-11-IDEX-007) operated by the French National Research Agency (ANR). The authors are grateful to Thibault Gajdos, Simon Grant, Anthony Marley, Ismael Rafai, Charlotte Saucet, Jean-Christophe Vergnaud and Marie Claire Villeval for their insightful comments. We also benefited from comments by seminars and conferences participants at Australian National University, $11^{\text {th }}$ ANZWEE (Brisbane), AMPC 2017 (Brisbane), $8^{\text {th }}$ ASFEE (Rennes), ESA World Meeting 2017 (San Diego), Université Nice Sophia Antipolis, University of Sydney. 
optimality. The second experiment explains the trade-off by the concern of people for being right.

Keywords: optimality; accuracy; signal detection theory; incentives; experiment. JEL codes: D81; D83; Y08.

\section{Introduction}

When making a choice under uncertainty, individuals aim to take the best decision. How to define the quality of a decision has been at the core of decision theory since its beginning. Normative models provide such a definition: the best solution is the one that respects some axioms of rationality and in fine maximizes the expected benefits of a decision. These expected benefits have been expressed in terms of expected values, expected utility or subjective expected utility. Such approaches, based on maximization of expectations, will define the best solution as the optimal one. But another side of the decision's quality can also be assessed: its accuracy. The decision taken may be accurate or inaccurate when the uncertainty is resolved. Overall the quality of a decision may be approached in terms of optimality and accuracy. In the common sense, both coincide: an accurate decision will also be the one that maximizes the expected benefits. But in fact, in a large number of real-life decisions, there exists a mechanism pushing for a divergence between these two behaviors. As soon as the stakes of the decisions are dependent of the states of nature, a potential asymmetry between reaching accuracy and being optimal may appear. As an example, consider a doctor who has to determine if a patient suffers from an illness. The doctor observes the patient's symptoms and these symptoms provide him evidence on the patient's medical condition. However symptoms are not clear enough to suppress the uncertainty about the condition. Because of this uncertainty, it is relevant for the doctor to also consider the consequences of his decision before establishing the diagnosis. The positive benefits of correctly diagnosing the patient as sick or sane are clearly overcame by the negative consequences of an incorrect diagnosis. Furthermore, within these mistakes, treating a sane patient has lower negative consequences than miss-

ing a disease. To account for this asymmetrical aspect of the consequences, a doctor, aiming for a diagnosis maximizing the expected consequences, should give up part of his accuracy when the patient is sane to increase his accuracy when the patient is sick. Thus maximizing expected consequences would lead to non-maximized accuracy. Through this example we can see that asymmetrical stakes between the outcomes of a decision imply a divergence between optimality and accuracy. Maximizing the expected value of a decision, when outcomes are different regarding the true state of nature, leads to less accurate de- 
cisions. Individuals face a trade-off between optimality (expected benefits maximization) and accuracy (success rate maximization).

In this paper, we provide an experimental setting in which consequences in two different states of nature are asymmetric. Facing an uncertain environment, an individual observes a noisy signal about the real state of nature. His decision can be classified as accurate or not according to the actual realization of the event. However successes and errors will have different consequences in each state. He can thus decide to base his behaviour on two alternative strategies: the optimal decision strategy and the accuracy-maximizing strategy. Aiming for optimality will reduce his accuracy, while targeting successes will decrease his expected benefits: he is facing a trade-off between optimality and accuracy. Our study is composed of two laboratory experiments pursuing two complementary objectives. The first experiment aims to highlight the existence of the optimality-accuracy trade-off and test its robustness to different settings (pure-loss decisions and optimality in terms of expected utility). The second experiment enables a direct evaluation of the role played by the value of being right in the observed optimality-accuracy trade-off.

The optimality-accuracy trade-off might play a crucial role in each decision under uncertainty involving asymmetric reward for different types of successes and errors. Going beyond medical decision-making, we can think about a response to a warning of danger, military decisions during conflicts, jury deliberations on the guilt of a defendant or trading decisions on a volatile market. However, to the best of our knowledge and despite its important questions about efficiency, experts' behaviors and payment schemes, the trade-off has never been extensively analyzed in the economics literature. We argue that it results from a methodological difficulty. As an answer, our approach is based on a computational model used in cognitive sciences. Using a perceptual task and a signal detection model, we study the optimality-accuracy trade-off and investigate the decision processes involved. Signal Detection Theory (SDT hereafter; Green and Swets, 1966; Wickens, 2001) offers a normative benchmark to understand how individuals make decisions under uncertainty. Individuals face a detection task in which they have to identify if a signal is present in a noisy environment. SDT provides theoretical foundations to identify the main components of the decision. It allows to disentangle the impact of the stimulus itself from the impact of the decision strategy. Applying this framework to the optimality-accuracy trade-off, it offers precise predictions of the expected behaviors as well as estimations of potential treatment effects. From a methodological point of view, SDT enables to compute decision strategies based on observed decisions and provides a powerful tool to evaluate the decisions resulting from an optimal or an accurate decision process. In a decision support tool perspective, the ability of SDT to identify the decision strategy is crucial. It allows us to know whether, for example, a poor performance is 
caused by a low discrimination of the signal - in which case little can be done to improve performance - or by a decision strategy not suited to achieve the desired goal - in which case improved performance may be possible by influencing this strategy. For these reasons, we argue that this analytical and experimental framework is the one appropriate to handle the optimality-accuracy question.

In the first experiment, we provide empirical findings on how people react to the optimality-accuracy trade-off. We vary incentives at a treatment level to compare situations with a difference between optimality and accuracy to situations without difference. We also investigate the impact of a pure-loss framework on the decisions by confronting individual to negative payoffs for both successes and errors. The impact of loss aversion on economic decisions has been extensively studied (Tversky and Kahneman, 1991; Wakker, 2010). However, to our knowledge, the optimality-accuracy trade-off has been highlighted only in mixed gain-loss framework but never in a pure-loss frame (Maddox et al., 2003b). By varying incentives and allowing pure-losses, we capture a wide range of decisions settings. We also assess the robustness of previous results to a change from optimality defined as maximizing expected values to an expected utility maximization.

This first experiment reveals a decision strategy that lies between optimal and accuracymaximizing strategies. However, it does not us enable to determine individuals' intrinsic motivations. Do individuals carry out an actual trade-off between seeking for the higher payoff or the higher success rate? Are individuals seeking for optimal decisions and cannot escape from a biased decision process leading to too much accuracy? To answer these questions, the second experiment introduces the concept of "value of being right". It represents how individuals value giving the correct answer outside of payoff considerations. This experiment investigates how important is the value of being right in the optimality-accuracy trade-off by comparing decisions with and without monetary incentives. We obtain that this value of being right plays a key role in the departure from optimality. Therefore, the observed trade-off is not only the consequence of a difficulty to reach optimality, but also a search for accuracy.

The remainder of this paper is organized as follows: Section 2 gives a brief theoretical background on SDT, related literature and introduces our hypotheses. Section 3 presents both experimental designs. The data analysis methodology and the results of our studies are in Section 4. Section 5 concludes. 


\section{Theoretical background and hypotheses}

\subsection{Signal Detection Theory}

SDT provides a general framework to describe and analyze perceptual decisions made under uncertainty. All models of detection should deal with at least two components of the detection decision: the sensory process, which converts the stimuli into an internal representation; and the decision process, which decides based on this representation what to answer. SDT, by combining detection theory and statistical decision theory, permits us to disentangle the decision process from the perceptual process involved in the task itself. SDT is thus used as a statistical tool to describe how individuals have made their decisions. We will also rely on a second aspect of SDT in this study: its ability to provide a characterization of an ideal observer's decision process. Given the perceptual characteristics of the task, we can make predictions about the decision process of a hypothetical agent using all the information available in an optimal (Bayesian) way. Comparing actual behaviors with the one of this ideal observer gives insight on the actual decision-making process of the individuals. We will first present the statistical aspect of SDT and show that we can infer the decision process based on actual choices. Then we will characterize how an ideal observer should behave and thus what is optimality in our decision framework.

Facing an uncertain situation, an observer has to detect if a noisy signal is present. SDT separates the decision-making process into two statistical elements: the discrimination (the perceptual properties of the task) and the criterion (the decision process used). The most natural setting of SDT is the following: a situation has two possible states of nature that are either "signal" or "noise". In state "signal", the signal adds up to some noise making its discrimination difficult. In state "noise", only noise remains and no signal is present. The observer faces briefly the situation and gathers evidence on the state of nature. Based on the level of this internal accumulation of evidence, he answers either "signal absent" or "signal present". There are four scenarios: correctly report that the signal is present ("hit"), incorrectly report that the signal is present ("false alarm"), correctly report that the noise is present ("correct rejection"), and incorrectly report that the noise is present ("miss"). Formally, the state of nature $\Theta$ takes values in $\{0,1\}$ with $\Theta=0$ meaning that the state of nature is "noise" and $\Theta=1$ meaning that the state of nature is "signal". The observer makes a decision $D$ taking values in the same space $(D=1$ meaning "signal present" and $D=0$ meaning "signal absent"). Table 1 summarizes the four possible outcomes.

The level of evidence, $X$, received by the observer on the state of nature is represented 


\begin{tabular}{ccc} 
& $\begin{array}{c}\text { Signal } \\
\Theta=1\end{array}$ & $\begin{array}{c}\text { Noise } \\
\Theta=0\end{array}$ \\
\hline $\begin{array}{c}\text { Signal present } \\
D=1\end{array}$ & Hit & False Alarm \\
\hline $\begin{array}{c}\text { Signal absent } \\
D=0\end{array}$ & Miss & Correct Rejection \\
\hline
\end{tabular}

Table 1: Outcome of a decision $(D)$ depending on the state of nature $(\Theta)$.

by a continuous random variable. It is informative on the state of nature as its distribution depends on this state. A higher level of evidence indicates a higher likelihood that the state of nature is "signal". The difficulty of the task depends on the shape of the densities associated with each state of nature (Figure $1-d$ ). The perceptual process is thus defined by this internal representation of evidence facing signal and noise situations. The distance between the modes of these two density functions measures the discrimination abilities of individuals facing the task. ${ }^{1}$ The level of discriminability between signal and noise impacts the different outcomes of the decision. For example, if there is a large overlap between the two conditional densities, the task is more difficult as the level of evidence received in the state of nature "noise" has a high probability of being received in the state of nature "signal". Note that this overlap implies that there will be always some errors in the decision process and explains why the choices are made under uncertainty. The information revealed by the level of evidence can be expressed as a likelihood ratio. This likelihood ratio is the ratio of the conditional probabilities of observing $X$, i.e. a unique quantity expressing the strength of evidence associated toward each state of natures.

$$
\forall X \in \mathbb{R}, \mathcal{L}(X)=\frac{\mathbb{P}(X \mid \Theta=1)}{\mathbb{P}(X \mid \Theta=0)}
$$

The observer has to decide when to answer "signal present". The decision strategy is summarized by the minimal value of the likelihood ratio required to answer "signal present". In other words, it represents the minimal strength of evidence in favor of the state of nature "signal" needed to answer "signal present". This threshold, which is the statistical measure of the decision process itself, is called decision criterion and noted $\beta$ (Figure 1 a and b). The decision can thus be expressed as:

$$
\forall(X, \beta) \in \mathbb{R}^{2}, D(X, \beta)= \begin{cases}1 & \text { if } \mathcal{L}(X) \geq \beta \\ 0 & \text { if } \mathcal{L}(X)<\beta\end{cases}
$$

When choosing his decision criterion, the observer faces a trade-off between the two types of correct decisions (hit and correct rejection). If the observer answers "signal

\footnotetext{
${ }^{1}$ In the experiments we will control for individual heterogeneity of discrimination abilities. Thus the discrimination is a pure measure of the task difficulty.
} 
present" more often, it increases his hit probability but decreases his correct rejection probability. The same mechanism applies if he sets his criterion according to the two types of errors (miss and false alarm) i.e. answering "signal present" more often decreases miss probability but increases false alarm probability. By observing the choices of subjects (and thus the proportions of each successes and errors types), we are able to estimate the criterion actually used by individuals facing the decision problem.

In order to estimate the model, one needs to assume a distribution of perceived evidence by the observer. For each state of nature, standard SDT assumes that the level of evidence coming from a noise $\left(X_{n}\right.$ or $\left.X \mid \Theta=0\right)$ or a signal $\left(X_{s}\right.$ or $\left.X \mid \Theta=1\right)$ follow Gaussian distributions (Gold and Shadlen, 2001, 2007). The key parameter is the difference in means between these distributions: the discrimination, $d^{\prime}$. The higher the discrimination parameter, the easier it is to discriminate the signal from the noise.

$$
X_{n} \sim \mathcal{N}\left(0, \sigma_{n}^{2}\right) \text { and } X_{s} \sim \mathcal{N}\left(d^{\prime}, \sigma_{s}^{2}\right)
$$

To decrease the number of parameters, it is possible to fix one of them. The convention is to fix the variance of noise to 1 . In addition, the model is commonly reduced to the equal variance SDT by assuming that the variances of the level of evidence in both state of nature are the same $\left(\sigma_{s}^{2}=\sigma_{n}^{2}=1\right)$. The specification has the advantage of being easily interpreted with one parameter referring to the difficulty of the task (the discrimination $d^{\prime}$ ) and the other referring to the decision strategy (the criterion $\beta$ ).

Overall, the statistical aspect of SDT allows for an estimation of the perceptual process via the discrimination ability and the decision process via the set of the decision criterion. As we consider that the observer is aware of the statistical properties of the signal and the noise but has no specific control over these properties, the perceptual process cannot be further investigated. On the contrary the decision process can be studied in a normative way. Depending on the decision goals the relative valuation of each type of correct answer will vary and results in different decision rules. These decision rules may follow different optimization targets and SDT provides a description of an ideal observer using these rules. $^{2}$ We distinguish two decision rules that maximize either the expected payoff or the accuracy (Figure 1 - c). We define the optimal observer as the observer maximizing the expected payoff of his decision. To maximize expected payoff, the relative valuation of a hit and a correct rejection must be equal to the relative payoffs' difference between a correct and an incorrect answer in both states of nature multiplied by the ratio of prior probabilities of each state. The decision criterion $\beta^{*}$ maximizing the expected payoff of

\footnotetext{
${ }^{2}$ Note that all decision rules based on likelihood ratio are optimal according to the Neymann-Person criteria as they maximize the hit rate for a given correct rejection rate (Neyman and Pearson, 1933).
} 
the decision is thus defined as:

$$
\beta^{*}=\frac{\Pi(\text { correct rejection })-\Pi(\text { false alarm })}{\Pi(\text { hit })-\Pi(\text { miss })} \times \frac{\mathbb{P}(\Theta=0)}{\mathbb{P}(\Theta=1)}
$$

with $\Pi$ the payoff associated to each outcome.

An observer maximizing the probability of giving a correct answer will value equally a hit and a correct rejection. He will answer the more likely of the two states of nature. The decision criterion $\beta^{a}$ maximizing the probability of success is thus equal to the ratio of prior probabilities of each state:

$$
\beta^{a}=\frac{\mathbb{P}(\Theta=0)}{\mathbb{P}(\Theta=1)}
$$

In our study, we focus on the opposition between accuracy and optimality induced by payoffs. The prior probabilities of both states of nature are chosen to be the same (equal base-rates; $\mathbb{P}(\Theta=1)=\mathbb{P}(\Theta=0))$. In equal base-rates, $\beta^{*}$ and $\beta^{a}$ are equal to:

$$
\beta^{*}=\frac{\Pi(\text { correct rejection })-\Pi(\text { false alarm })}{\Pi(\text { hit })-\Pi(\text { miss })} \text { and } \beta^{a}=1
$$

Thus, SDT provides a normative framework for the decision process of an ideal observer using a criterion maximizing expected payoffs and a criterion maximizing success rates. While these two criteria can be defined as optimal in the sense that they come from an ideal observer, we state the optimal criterion as the one that maximizes the expected payoffs of the decision i.e. that provides optimal monetary performances facing the decision. ${ }^{3}$

In the present paper we will use both aspects of SDT. The ideal observer theory will give predictions on how an individual maximizing expected payoffs or maximizing accuracy will behave. The statistical decision theory will be used to infer measurements on actual perceptual and decision processes of our subjects. By comparing ideal and observed behaviors, we will be able to see if individuals facing asymmetrical stakes decisions are able to reach the optimal performances in terms of payoffs or if they are more pulled toward accuracy.

\section{$2.2 \quad$ Related literature}

The optimality-accuracy trade-off has been extensively studied in cognitive sciences. Various methods to induce an asymmetrical situation have been proposed, as well as different modelizations of these situations. While most of the studies are in psychology, some

\footnotetext{
${ }^{3}$ See Rahnev and Denison (2017) for a consideration and a literature review about (sub)optimality of perceptual decision in Bayesian frameworks.
} 

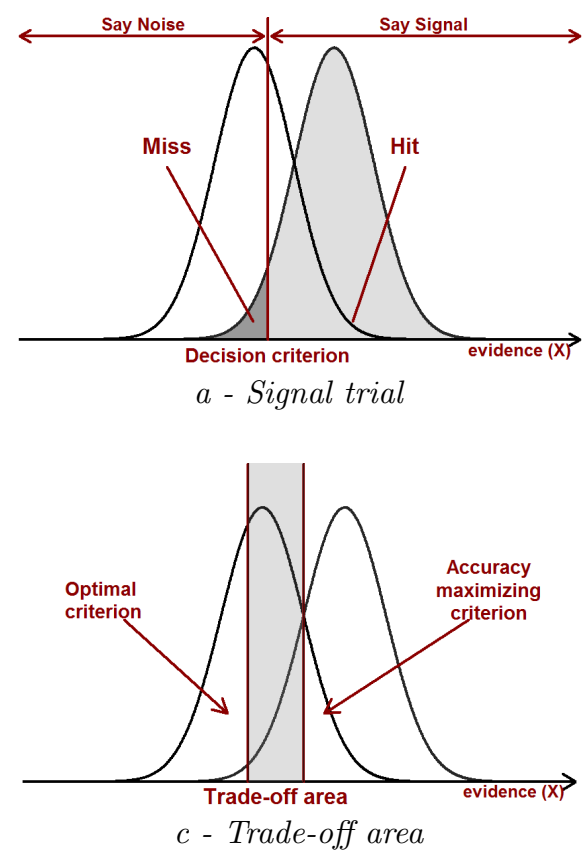
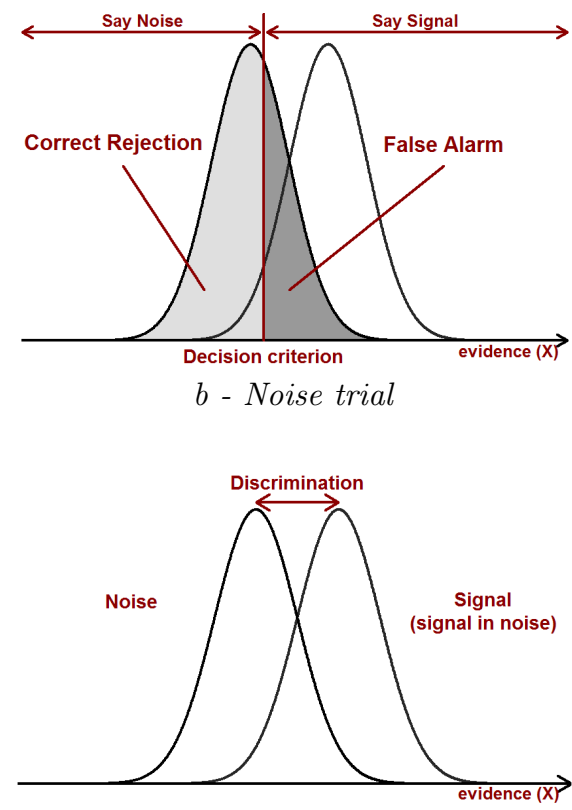

$d$ - Discrimination

Figure 1: The different components of Gaussian equal variance SDT.

Reading note: Figure a and Figure $b$ give the decision as a function of the criterion and the level of evidence. The shaded areas represent the corresponding probabilities of each outcome. Figure c plots, for an asymmetry toward signal, the trade-off area i.e. the set of criteria between the optimal and the accurate criterion. Figure d represents discrimination based on the distribution of the level of evidence coming from a noise and a signal.

attempts to explain the observed behaviors have been proposed using an economic framework.

Using SDT, asymmetry is induced by manipulating either the probabilities of each state of nature (base-rates) or the payoffs. In the literature, payoff manipulations include the introduction of non-zero cost or a loss for some outcomes (Barkan et al., 1998; Maddox et al., 2003b; Maddox and Bohil, 2005), the multiplication of payoffs (Galanter and Holman, 1967; Maddox et al., 2003b) or combinations of the previous manipulations with different discriminations (Bohil and Maddox, 2001, 2003). Facing these changes in incentives, individuals use a decision strategy that is too close to the accuracy-maximizing decision strategy to reach optimality. When all payoffs are increased the decision strategy is closer to optimality. Introducing non-positive payoffs or decreasing the discrimination has opposed consequences. Facing asymmetry at the base-rate level, individuals also use decisions strategies that are between the accuracy and the optimal decision strategy. Indeed, the probability that individuals report the more likely of both states of nature is lower than its prior probability. However, individuals tend to be closer to optimality facing base-rate inequalities than equivalent payoff asymmetries (Maddox and Bohil, 1998; Maddox and Dodd, 2001; Maddox and Bohil, 2005). The assertion that individuals use a 
decision strategy too close to the accuracy-maximizing decision strategy is dependant on how optimality is defined. Papers formerly mentioned are in line with SDT founding work (Green and Swets, 1966) as they consider optimality as the payoff maximizing strategy. However, in a utility approach the subjective distortion of payoffs and probabilities leads us to reconsider the optimal criterion. While Lynn and Barrett (2014) promote a utilitybased SDT, Ackermann and Landy (2015) use individual weighting-functions to derive Prospect Theory optima. They conclude that the shift from expected payoff to expected utility maximization reduces the gap between optimality and accuracy. However, the shift is not strong enough to suppress the gap.

The present work complements existing researches on several points. First, we highlight the existence of the trade-off using a yes/no detection task while previous studies implement two-alternative force choice (2AFC) task. ${ }^{4}$ In real-life situations high stakes are caused by the signal (e.g. a disease for a doctor, or danger for soldiers). Contrary to a 2 AFC setting, our framework enables us to reproduce the link between signal and high stakes, increasing the external validity of the results. Second, the impact of losses on the trade-off has been highlighted only in mixed gain-loss frameworks but never in a pure-loss frame. However, the non-separability between the valuation of gain and loss reveals the importance to isolate losses from gains to study the loss impact (Wu and Markle, 2008). As an answer, we implement an innovative pure-loss framework to link the impact of losses on decisions to the optimality-accuracy trade-off reaction. Third, using individual risk preferences estimations we are able to challenge previous insights about the potential importance of a utility framework to assess the trade-off.

Different explanations have been investigated to sort out the origin of the optimalityaccuracy trade-off. The first category of explanations is based on the idea that, as individuals face multiple consecutive decisions, what matters most is not the ex-nihilo optimal solution but the path of optimization (Roth and Erev, 1995). Based on this idea, Maddox and Bohil (2005) argue that the maximization process does not converge to optimality as the slope of the reward function in a neighborhood of the optimal solution is not steep enough to enable individuals to reach optimality (flat-maxima hypothesis). If individuals initiate their maximization process at the equal-probability/equal-payoff solution, it would converge to an overly accurate solution. The outcome bias may also affect the path of optimization. As the decision is taken under uncertainty a correct answer is not always an optimal answer. Overestimating the meaning of a correct answer would result in an outcome bias (Alicke et al., 1994; Baron and Hershey, 1988; Gino et al., 2010). Erev (1998) states that the path of optimization does not converge to optimality, as a

\footnotetext{
${ }^{4}$ In yes/no detection tasks, the signal is either present or absent. In 2AFC task, the signal is always present and individuals have to choose its location between two options.
} 
non-optimal strategy may be reinforced by positive rewards. In the same modelization framework, Myung and Busemeyer (1989) and Busemeyer and Myung (1992) find support for two different maximization processes, based either on a first or second order analysis of the criterion adjustment. The error correction model assumes that the magnitude of the stopping criterion is increased following an incorrect diagnosis while the hill climbing model states that the direction of adjustment changes after wrong answers.

A second category of explanations relies on the theory that participants emphasize accuracy over optimality. Several studies have concluded that there exists a tendency for individuals to give over-accurate answers (Maddox and Bohil, 2003, 2004; Balci et al., 2011; Bogacz et al., 2006). Their approach is based on model comparisons with a goodnessof-fit analysis. As a result, Maddox and Bohil (2003, 2004) argue that subjects attempt to maximize payoffs on each trial, but erroneously believe that maximizing accuracy fulfills this objective. This over-accuracy has also been interpreted as an induced value associated with successes. In a related setting based on unequal base-rates, Siegel (1959) concludes that individuals classifying correctly the less likely outcome benefit from an additional non-monetary reward compared to correct classification of the more likely outcome. Our approach is based on a novel design enabling a direct evaluation of the value of being right and thus challenges previous studies showing that over-accuracy results from a biased search of optimality.

\subsection{Hypotheses testing}

Based on the results of the literature, our two studies aim to test a set of five hypotheses.

Experiment 1 enables to test the following hypotheses:

$\mathbf{H}$ 1.1. The observed decision criterion is lower bounded by the optimal decision criterion.

$\mathbf{H}$ 1.2. The observed decision criterion is upper bounded by the accuracy-maximizing decision criterion.

Satisfying Hypothesis 1.1 and Hypothesis 1.2 gives the existence of the optimalityaccuracy trade-off (cf. Figure $1-\mathrm{c}) .^{5}$

$\mathbf{H}$ 1.3. The observed decision criterion is closer to the accuracy-maximizing decision criterion than to the optimal decision criterion.

Hypothesis 1.3 investigates whether one of the two concepts may have a leading role in the trade-off. Accuracy maximization is a natural behavior and requires only to assess information coming from the stimulus. An optimal behavior also requires to assess

\footnotetext{
${ }^{5}$ The range of the bounds comes from the asymmetry toward signal; an asymmetry towards noise would reverse this range.
} 
information from the payoff matrix and to aggregate them optimally with stimulus information. We thus hypothesize that optimality is harder to reach.

$\mathbf{H}$ 1.4. The observed decision criterion and discrimination are affected by the decision under loss.

Hypothesis 1.4 assesses the robustness of the previous hypotheses to decisions under loss.

$\mathbf{H}$ 2.1. The optimality-accuracy trade-off is not only the consequence of a sub-optimal maximization process, but also a reaction to the intrinsic valuation of being right.

Experiment 2 is designed to assess Hypothesis 2.1. More precisely, it investigates if the trade-off may take its roots in a mixed valuation of accuracy and optimality. To test this hypothesis, we need to disentangle the monetary incentives of giving a correct answer - as correct answers are more rewarded than errors - from the intrinsic motivation of being right. We implement two treatments: a treatment with higher payoffs for successes than for errors and a treatment without incentives on the quality of the decision. The incentivized treatment implements symmetric payoffs (same payoff for both types of successes and same payoff for both kinds of errors) such that accuracy and optimality are perfectly aligned. Thus maximizing only payoffs or a combination of accuracy and optimality lead to the same decision strategy $\left(\beta^{*}=\beta^{a}=1\right)$. In the flat payoff treatment, an individual valuing the fact of being right should maintain the same decision strategy as accuracy is still maximized by $\beta^{a}=1 .^{6}$ In contrast, a pure-payoff maximizer should approach random guesses as all decisions give him the same level of satisfaction. Thus, if a change in behaviors is observed between both treatments the optimality-accuracy trade-off is only the consequence of a maximization process unconsciously biased towards accuracy. Otherwise, the value of being right plays a role in the trade-off.

\section{Design}

Both experiments consisted of a series of individual perceptual decisions organized in a block/trial architecture. Each block represents a treatment while each trial represents a decision. To make a decision, subjects received two different types of information: a signal-in-noise stimulus and a payoff matrix. Facing the stimulus, they formed beliefs on whether it is a signal or a noise. The payoff matrix provided a matching rule between the four possible decision outcomes and the payoffs. By combining both information, they had to choose to answer either "signal present" or "signal absent". Treatments

\footnotetext{
${ }^{6}$ Even if the decision strategy is kept constant the effort invested may be different. This is captured by the discrimination term.
} 

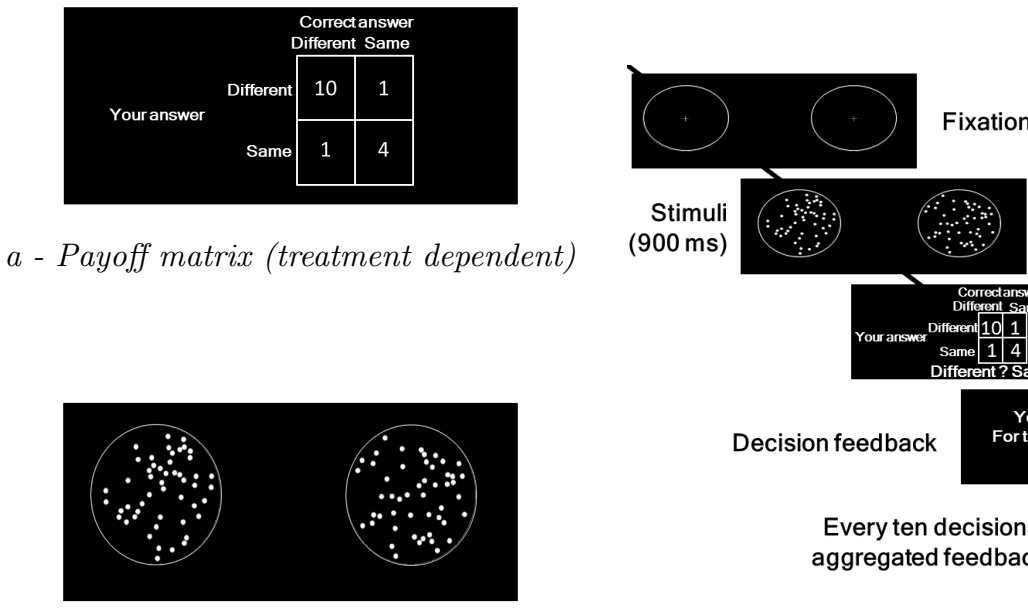

$b$ - Stimuli (trial dependent)

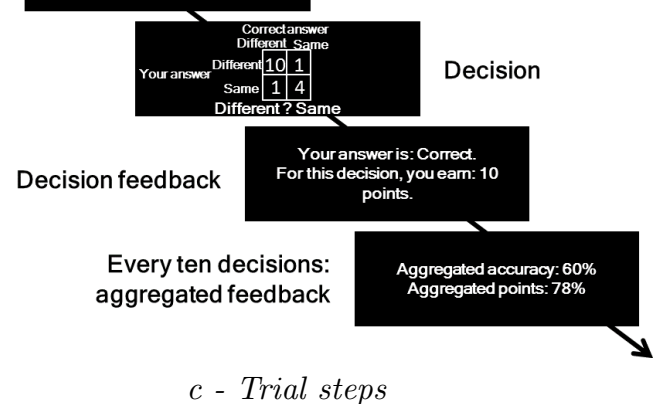

Figure 2: Trial proceedings.

Reading note: (a) Payoff matrix: Subjects were informed of the payoff matrix at the beginning of treatments and this matrix was then displayed on the screen when they made their decision. (b) Example of stimuli. (c) Trial steps were: fixation, stimuli display (900 ms), decision and feedback. Every ten trials aggregated feedback constituted the last trial step.

corresponded to variations in the payoff matrix. Both studies used the same stimulus but differed mainly regarding the treatments implemented. In Experiment 1, prior to the main section, we elicited attitudes toward risk, ambiguity and loss. This preferences elicitation was not present in Experiment 2 as risk and loss attitudes are not central in this experiment. At the end of both experiments subjects had to answer a standard demographic questionnaire.

In this section, we present the main perceptual task, the preferences elicitation mechanism, the experimental procedures and our sample of subjects. Figure 2 gives an overview of a trial proceeding.

\subsection{Stimuli}

For both studies we used a variation of the perceptual task used by Massoni et al. (2014) and Hollard et al. (2016) to study subjective beliefs: a yes/no signal-in-noise stimulus. Subjects faced two circles with a certain number of dots in each one. They had to determine if there was a difference in dots between circles ("signal present") or if they contained the same number of dots ("signal absent"). Dots were randomly displayed in two circles during $900 \mathrm{~ms}$. When signal was the correct answer ("signal trial"), one circle always contained 50 dots while the other contained more dots. The position of the target 
circle (on the left or right) was randomly chosen on each trial. When noise was the correct answer ("noise trial"), both circles contained the same number of dots (50). The short display time and the randomness of the dots localization made counting dots impossible for subjects causing the uncertainty in the decision. To have a neutral framework, noise was referred as "Same" and signal as "Different" during the experiment. Before and after the stimulus display subjects faced a fixation screen (the fixation screen was composed of both circles without dots but a cross in the middle of each one of them). The first fixation was used to direct subject's attention to the future location of the stimulus. The second one enhanced stimulus information processing after the end of the stimulus display. To increase control we i) calibrated the task difficulty at the subject level, and ii) randomly generated stimuli prior to the experiment by difficulty levels. The stimuli difficulty was given by the difference in the number of dots between the two circles in signal trials (hereafter referred as $x_{c}$ ). The calibration of the difficulty of the task was done using a psychophysical staircase at the subject level in order to control for individual heterogeneity of visual abilities (Levitt, 1971). ${ }^{7}$ In this non-incentivized calibration period, subjects received only the stimulus information and had to determine if the stimulus were either in a noise or a signal state. Feedback on decision accuracy was provided after each decision. The targeted success rate was $71 \%$. This level was chosen for subjects to outperform random guesses (relevance of the stimulus) and to avoid being too close to perfect discrimination (relevance of the payoff matrix). For the same level of calibration, we presented the exact same set of stimuli to participants in each block by difficulty level. Stimuli were randomly generated prior to the experiment under constraints concerning dots spacing. ${ }^{8}$ Signal and noise trials frequencies were controlled to be exactly equal and the sequence was reproduced from one block to another.

\subsection{Payoff matrices}

To implement the asymmetrical framework we fixed base-rates but manipulated the payoff matrices. Experiment 1 was based on 4 different matrices (one symmetric, three asymmetric) while Experiment 2 was based on two matrices (one symmetric and incentivized - same as Experiment 1 - and one with flat payoffs). Both studies were within-subject experiments. The order of treatments was randomized at a subject level.

\footnotetext{
${ }^{7}$ The psychophysical staircase used was a one-up two-down staircase in which one dot was removed after two consecutive correct answers and one dot was added after one failure. The calibration ended when subjects had achieved 35 reversals in the staircase (a reversal means a change in the $x_{c}$ 's value). The number of dots difference $x_{c}$ used in the experiment was computed as the mean dots number across the two last reversals of the staircase.

${ }^{8}$ All dots were of the same size (diameter $0.4^{\circ}$ ) and the average distance between dots was kept constant. They appeared at random positions inside two outline circles (diameter $5.1^{\circ}$ ) first displayed with fixation crosses at their centers at eccentricities of $\pm 8.9^{\circ}$.
} 
Experiment 1 - Experiment 1 aimed to measure the difference in behaviors resulting from asymmetrical stakes. Out of the four payoff matrices used, three generated asymmetric payoffs and one induced symmetric payoffs. All asymmetries were biased toward signal to increase external validity. ${ }^{9}$ Payoff matrices can be expressed using the two free parameters presented in Table 2. The $a$ parameter introduces the optimality-accuracy trade-off by creating an asymmetry between both kinds of successes and $t$ translates the payoff matrix. ${ }^{10}$ The "Symmetric Treatment" corresponded to $t=m=0$. Subjects earned the same payoff when the correct answer is signal or noise. The "Loss Treatment" induced an asymmetry while staying as close as possible from the Symmetric Treatment: $t=0, a=3$. The "Loss Treatment" was the minimal translation from Low Gain Treatment inducing losses for all outcomes: $t=-11, a=3$. The "High Gain Treatment" was obtained from the Low Gain Treatment after a positive translation matching the norm of the translation between Loss and Low Gain Treatments: $t=11, a=3$. This design enabled us to implement a pure-loss treatment as even with only incorrect answers in loss decisions, subjects were covered by their decisions in gain and still obtained an overall positive payment. ${ }^{11}$

\begin{tabular}{ccc} 
& $\begin{array}{c}\text { Different } \\
\text { No. of dots } \\
\Theta=1\end{array}$ & $\begin{array}{c}\text { Same } \\
\text { No. of dots } \\
\Theta=0\end{array}$ \\
\hline $\begin{array}{c}\Theta=1 \\
D=1\end{array}$ & $\mathbf{7 + t + a}$ & $\mathbf{1 + t}$ \\
\hline $\begin{array}{c}\text { "Same" } \\
D=0\end{array}$ & $\mathbf{1 + t}$ & $\mathbf{7 + t - a}$ \\
\hline
\end{tabular}

Table 2: Experiment 1 - Payoff matrix (payoff of a decision, $D$, depending on the state of nature, $\Theta)$.

Treatments: "Symmetric Treatment" $(t, a)=(0,0)$ i.e. $\left[\begin{array}{ll}7 & 1 \\ 1 & 7\end{array}\right]$; "Low Gain Treatment" $(t, a)=(0,3)$ i.e. $\left[\begin{array}{cr}10 & 1 \\ 1 & 4\end{array}\right]$; "Loss Treatment" $(t, a)=(-11,3)$ i.e. $\left[\begin{array}{cc}-1 & -10 \\ -10 & -7\end{array}\right]$ and "High Gain Treatment" $(t, a)=(11,3)$ i.e. $\left[\begin{array}{ll}21 & 12 \\ 12 & 15\end{array}\right]$.

Experiment 2 - Experiment 2 consisted of the previous Symmetric Treatment and a

\footnotetext{
${ }^{9}$ As an example in cancer detection, security control or response to warning of danger, the signal situation is respectively a tumor, a harmful individual or a threat. They are the high stakes situations.

${ }^{10}$ In most real world situations (e.g. medical decision-making), the asymmetry between answers' stakes is induced by an asymmetry of both successes and errors. Model predictions do not vary for an asymmetry induced by successes, errors or both, however the behavioral impact is an open question. As studying this phenomena is not in the scope of this paper, we choose to induce asymmetry by varying only successes' payoffs to decrease the difficulty of the task and thus to reduce the noise in the evaluation of the trade-off.

${ }^{11}$ Following the payment rule detailed in Subsection 3.5, a subject giving only incorrect answers would have received: 20 points $(5 \times 1$ point in the Symmetric Treatment, $5 \times 1$ point in the Low Gain Treatment, $5 \times-10$ points in the Loss Treatment and $5 \times 12$ points in the High Gain Treatment).
} 
new flat payoff matrix as described in Table 3. This payoff matrix enabled us to have a flat payment with minimal departure from the Symmetric Treatment. For sake of clarity, Experiment 2 treatments are referred as "Incentivized Treatment" and "Flat Treatment".

\begin{tabular}{|c|c|c|c|c|c|}
\hline & $\begin{array}{c}\text { Different } \\
\text { No. of dots } \\
\Theta=1\end{array}$ & $\begin{array}{c}\text { Same } \\
\text { No. of dots } \\
\Theta=0\end{array}$ & & $\begin{array}{c}\text { Different } \\
\text { No. of dots } \\
\Theta=1\end{array}$ & $\begin{array}{c}\text { Same } \\
\text { No. of dots } \\
\Theta=0\end{array}$ \\
\hline $\begin{array}{c}\text { "Different" } \\
D=1\end{array}$ & 7 & 1 & $\begin{array}{c}\text { "Different" } \\
D=1\end{array}$ & 4 & 4 \\
\hline $\begin{array}{c}\text { "Same" } \\
D=0\end{array}$ & 1 & 7 & $\begin{array}{l}\text { "Same" } \\
D=0\end{array}$ & 4 & 4 \\
\hline
\end{tabular}

Table 3: Experiment 2 - Payoff matrix (payoff of a decision, $D$, depending on the state of nature, $\Theta$ ).

\subsection{Feedback}

To help subjects in their decision-making process, we provided them with two types of feedback. We aimed to not influence participants to consider either more the stimulus or the payoff matrix. Thus, we gave them feedback on the stimulus - if their decisions were correct or incorrect - and feedback on the payoff matrix - payoff earned for the decision. In addition to trial-by-trial feedback subjects received every 10 decisions two types of aggregated feedback. First, we showed their success rate for the last 10 decisions. Second, we provided aggregated payoff feedback indicating how close they were from optimality in terms of payoffs during the last 10 decisions. ${ }^{12}$ Our aggregated payoff feedback is based on the additional payoff earned for a correct answer to reflect the performance of subjects without being influenced by any endowment effect. Feedback effects have been highlighted in perceptual tasks using for example objective, optimal or delayed feedback (Maddox and Bohil, 2001; Maddox et al., 2003a; Ell et al., 2009). Including accuracy feedback was important to limit the formation of biased beliefs on performances. The optimality feedback motivation is two-fold. First, it balances accuracy and optimality regarding feedback. Second, as experiments are based on payoff manipulations, it was important to ensure that subjects were assessing correctly the impact of their decisions. Optimality feedback works as a recall on the payoffs implication of each decision.

\footnotetext{
${ }^{12}$ The aggregated payoff feedback (apf) is given by:

$$
\forall(x, y, z) \in \mathbb{R}^{3}, \operatorname{apf}(x, y, z)= \begin{cases}\frac{x-y}{z-y} & \text { if } z>y \\ 1 & \text { if } z=y\end{cases}
$$
}

With $x$ actual payoffs for the last 10 decisions, $y$ payoffs if all answers would have been incorrect, $z$ payoffs if all answers would have been correct. 


\subsection{Preference elicitation: attitudes toward risk, ambiguity and loss}

We reproduced the risk, ambiguity and loss preferences elicitation task of Dai et al. (2017) which is based on Eckel and Grossman (2008) method with the presentation proposed by Eckel et al. (2012). This mechanism has the advantage of being cognitively simple for subjects and giving less noisy estimates than more complex measures (Dave et al., 2010). The preferences elicitation task was composed of four successive lotteries decisions. Subjects had to select a two-outcome lottery out of six possibilities. Lottery sets differed from one another regarding likeliness of each outcome and the fact that outcomes can induce a loss. For "Decisions 1" and "Decision 2" (see Supplementary Information, hereafter SI, Figure 1 - a and b), each outcome was equally likely - decisions under risk. For "Decisions 3" and "Decision 4" (SI Figure 1 - c and d), the probability of each outcome varied between $30 \%$ and $70 \%$ - decisions under ambiguity. For Decisions 1 and 3 losses were impossible - decisions under gain - while some outcomes resulted in losses for Decisions 2 and 4 decisions under loss. Outcome earnings were constructed as follow: moving clockwise the expected payoff and its variance increased, exception made of the last lottery (A) for which only the variance of the payoff was higher compared to the previous one (F) (cf. SI Figure 1 for the visual design). Lotteries of decisions under loss are obtained after subtracting a fix amount from lotteries of decisions under gain. This amount is allocated to subjects as an endowment for decisions under loss.

\subsection{Experimental procedures}

All sessions of both experiments were conducted at Queensland University of Technology (QUT) in September 2016. Subjects were students from QUT and were enrolled using ORSEE (Greiner, 2015). Experiments have been programmed using MATLAB with the Psychophysics Toolbox version 3 (Brainard, 1997) and have been achieved on computers of resolution $1920 \times 1080$. Concerning the main task, $10 \%^{13}$ of participants' decisions were converted into payments at a rate of 8 points $=A U D 1^{14}$ In Experiment 1 where the preference task was present, one decision was randomly selected to add up to total earnings $(2 E C U=A U D 1)$.

The first experiment was 90 minutes long and paid in average AUD 27.0. The second experiment was half as long and paid in average 10.5 AUD. In total 84 subjects participated in these studies across 3 sessions per experiment. The 41 subjects involved in

\footnotetext{
${ }^{13}$ There are 20 paid decisions out of 200 in Experiment 1 and 10 paid decisions out of 100 in Experiment 2. The number of decisions paid per block was controlled to be equal.

${ }^{14}$ Payoffs were referred to as "points" during both studies.
} 
Experiment 1 were on average 22.5 years old, $56 \%$ of them were males. The 43 subjects involved in Experiment 2 were on average 23.2 years old, $63 \%$ of them were males.

\section{Methodology and results}

We present the methodology used to analyze experimental data in Subsection 4.1. For both studies, we combine SDT-based analyzes (Subsection 4.2.2, Subsection 4.3.2) and SDT-free analyzes (Subsection 4.2.1, Subsection 4.3.1) to provide an extensive discussion of our hypotheses set.

\subsection{Methodology}

SDT-based estimations and model predictions - Empirically, SDT allow us to compute estimators of the decision criterion and the discrimination based on the observer's percentage of hits (hit rate) and percentage of false alarms (false alarm rate). For $n$ decisions, divided in $n_{s}$ signal trials and $n_{n}$ noise trials, the hit rate $(H R)$ and the false alarm rate $(F A R)$ are computed using the number of times subjects answer signal in both types of trials:

$$
H R=\frac{\sum_{i=1}^{n_{s}} \mathbb{1}\left(D_{i}=1\right)}{n_{s}} \text { and } F A R=\frac{\sum_{i=1}^{n_{n}}\left(\mathbb{1}\left(D_{i}=1\right)\right)}{n_{n}}
$$

The probabilities of hit $\left(P_{H}\right)$ and false alarm $\left(P_{F A}\right)$ are given by (proof in SI A.):

$$
\begin{gathered}
P_{H}=\mathbb{P}(D=1 \mid \Omega=1)=1-\phi\left(\frac{\log (\beta)}{d^{\prime}}-d^{\prime} / 2\right) \\
P_{F A}=\mathbb{P}(D=1 \mid \Omega=0)=1-\phi\left(\frac{\log (\beta)}{d^{\prime}}+d^{\prime} / 2\right)
\end{gathered}
$$

Hit or false alarm rates equal to 0 or 1 prevent robust estimations. Following the recommendations from Brown and White (2005), we use the log-linear correction proposed by Hautus (1995) for estimations:

$$
H R_{C}=\frac{0.5+\sum_{i=1}^{n_{s}} \mathbb{1}\left(D_{i}=1\right)}{n_{s}+1} \text { and } F A R_{C}=\frac{0.5+\sum_{i=1}^{n_{n}}\left(\mathbb{1}\left(D_{i}=1\right)\right)}{n_{n}+1}
$$

With $H R_{C}$ the corrected hit rate and $F A_{C}$ the corrected false alarm rate.

By finding the couple of parameters $\left(\hat{\beta}, \hat{d}^{\prime}\right)$, the most likely to have produced the actual $H R_{C}$ and $F A R_{C}$, we are able to predict SDT parameters based on observed data (left 
side of Figure 3).

We are interested in the effects of decision strategies' changes for an exact same level of perceptual abilities. We thus derive model predictions by replacing the decision strategy by either the optimal decision strategy or the accuracy maximizing decision strategy and by keeping constant the discrimination term. We use a two-step approach. We first estimate $\left(\hat{\beta}, \hat{d}^{\prime}\right)$ then replace $\hat{\beta}$ by their theoretical values from optimal or accurate behaviors and compute the couple $\left(\hat{P}_{H}, \hat{P}_{F A}\right)$ (right side of Figure 3 ). Based on $\hat{P_{H}}$ and $\hat{P}_{F A}$, we are able to derive the predicted probability of success (success rate; $\hat{R}_{S}$ ) and the expected payoff per trial $\left(\hat{E}_{P}\right)$. Total payoffs for series of trials are obtained by multiplying $\hat{E}_{P}$ by the number of trials.

$$
\begin{gathered}
\hat{R}_{S}=\frac{\hat{P}_{H}+\left(1-\hat{P}_{F A}\right)}{2} \\
\hat{E}_{P}=\hat{P}_{H} \times \Pi(\text { hit })+\left(1-\hat{P}_{H}\right) \times \Pi(m i s s)+\left(1-\hat{P}_{F A}\right) \times \Pi(C R)+\hat{P}_{F A} \times \Pi(F A) \\
=\hat{P}_{H}[\Pi(\text { hit })-\Pi(\text { miss })]+\hat{P}_{F A}[\Pi(F A)-\Pi(C R)]+\Pi(m i s s)+\Pi(C R)
\end{gathered}
$$

with $\Pi$ the payoff associated to each outcome, FA the false alarm and CR the correct rejection.

We predict behaviors for the two opposed decision strategies involved in the optimalityaccuracy trade-off: $\beta^{*}$, the optimal strategy and $\beta^{a}$, the accuracy-maximizing strategy (Subsection 2.1). For the symmetric treatment $\beta^{*}=1$ and for asymmetric treatments $\beta^{*}=\frac{1}{3}$. For all treatments $\beta^{a}=1$.

Estimations of attitudes toward risk, ambiguity and loss - We derive two types of estimations at a subject-level: model-free estimations based on two-by-two comparisons of decisions and model-based estimations based on the decision in gain under risk. All model-free variables defined take three modalities: averse, neutral or seeker. To define the loss aversion under risk we compare risky lotteries with and without losses (Decision 2 and Decision 1). ${ }^{15}$ By comparing lotteries under ambiguity (Decision 3 and 4), we obtain the loss attitude under ambiguity. Ambiguity attitudes are defined by comparison to risk attitudes. Thus to find the ambiguity attitude under gain, we compare the lotteries in gain under ambiguity and under risk (Decision 3 and Decision 1). Finally, to compute the ambiguity attitude under loss we compare decisions under loss (Decision 2 and 4).

Model-based estimations consist of the estimation of constant relative risk aversion (CRRA) parameter intervals based on the decision in gain under risk. This specification of risk attitude has been chosen in compliance with influential experimental literature in risk preferences estimation (Andersen et al., 2008; Wakker, 2008; Dohmen et al., 2011;

\footnotetext{
${ }^{15}$ If subjects accept a higher level of risk in the gain frame (Decision 1) than in loss frame (Decision 2 ), they are identify as "loss averse under risk". If they accept a higher level of risk in the loss frame, they are identify as "loss seeker under risk". Subjects giving the same answer are identify as "loss neutral under risk". The same method is used for the other two-by-two comparisons.
} 


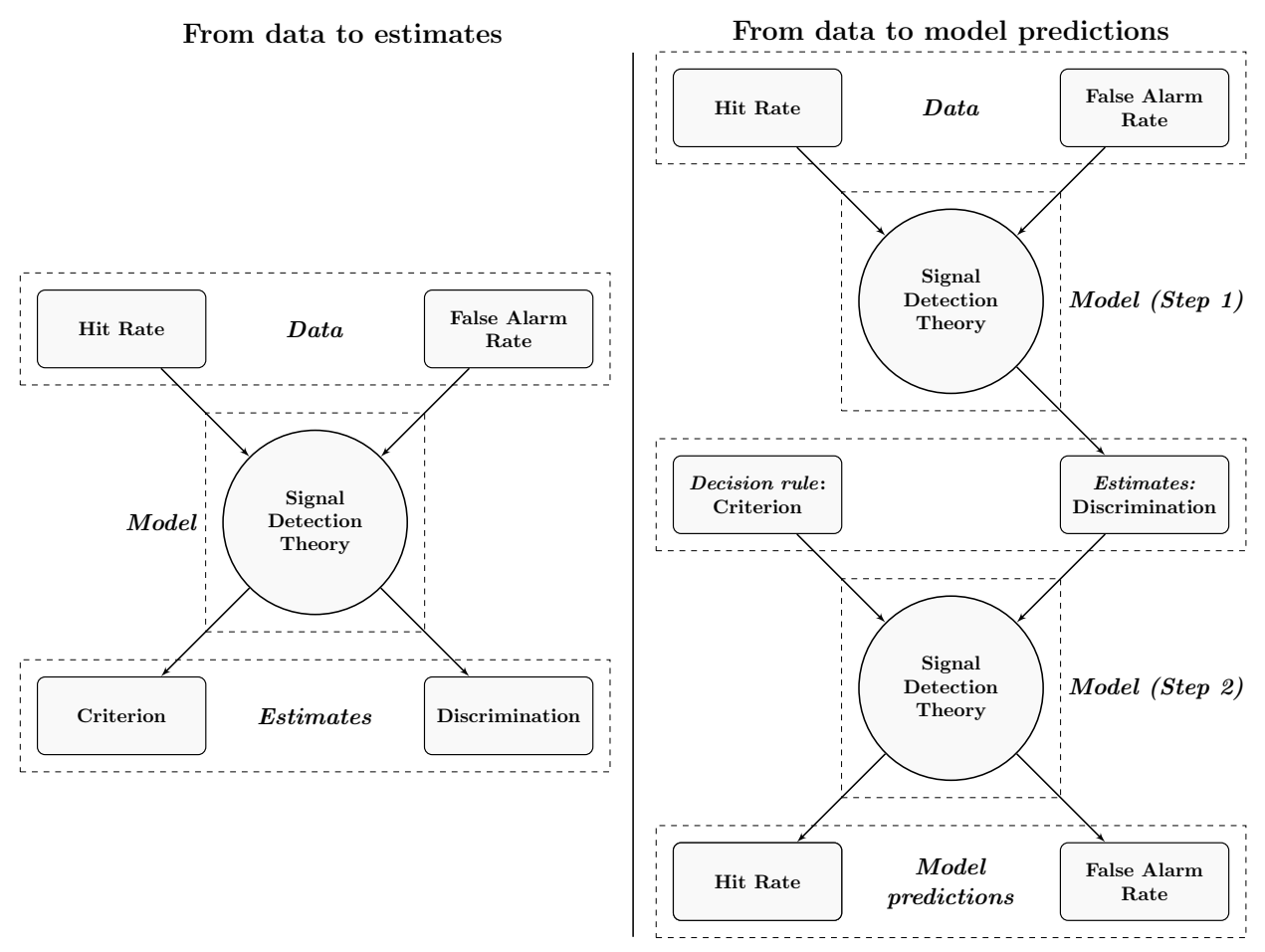

Figure 3: Discrimination and criterion estimations based on SDT modelisation.

Machina and Viscusi, 2013). The CRRA utility function can be expressed as:

$$
\begin{gathered}
\forall x \in \mathbb{R}^{+}, U(x)= \begin{cases}\frac{x^{\left(1-\gamma_{G}\right)}}{1-\gamma_{G}} & \text { if } \gamma_{G} \neq 1 \\
\ln (x) & \text { if } \gamma_{G}=1\end{cases} \\
\forall x \in \mathbb{R}^{-}, U(x)= \begin{cases}-\lambda \frac{(-x)^{\left(1-\gamma_{L}\right)}}{1-\gamma_{L}} & \text { if } \gamma_{L} \neq 1 \\
-\lambda \ln (-x) & \text { if } \gamma_{L}=1\end{cases}
\end{gathered}
$$

with $x$ the payoff, $\gamma_{G}$ and $\gamma_{L}$ the coefficients of risk aversion in the gain and the loss domains and $\lambda$ the coefficient of loss aversion.

Using the decision in gain under risk (Decision 1), we estimate a parameter interval for each decision (Table 4). ${ }^{16}$ From left to right, individuals are less risk averse implying a decrease in their CRRA parameter.

\subsection{Results - Experiment 1}

To investigate Hypothesis 1.1 to Hypothesis 1.4, Experiment 1 results are first assessed on a SDT-free base before estimating the quality of predictions at a subjects-treatments level and finally at a decision level. SDT-free analyses are mainly dedicated to evaluate the SDT-free Hypothesis 1.4 on decisions under loss.

\footnotetext{
${ }^{16}$ See SI D.1 for details.
} 


\begin{tabular}{lllllll}
\hline \hline Lottery & $\mathrm{B}$ & $\mathrm{C}$ & $\mathrm{D}$ & $\mathrm{E}$ & $\mathrm{F}$ & $\mathrm{A}$ \\
\hline Low Payoff & 7 & 6 & 5 & 4 & 3 & 0.5 \\
High Payoff & 7 & 9 & 11 & 13 & 15 & 17.5 \\
$\gamma_{G} \in$ & ] $3.45 ; \infty[$ & ] $1.16 ; 3.45[$ & ] $0.7 ; 1.16[$ & ] $0.49 ; 0.7[$ & ] $0 ; 0.49[$ & ]$-\infty ; 0[$ \\
$N(\%)$ & 2.4 & 26.8 & 24.3 & 4.9 & 17 & 24.6 \\
\hline
\end{tabular}

Table 4: CRRA parameter $\left(\gamma_{G}\right)$ intervals for the decision in gain under risk (Decision 1).

\subsubsection{SDT-free analysis at a decision level}

Table 5 presents the estimation results ${ }^{17}$ (cf. SI Table 1 for descriptive statistics).

Dependent variables - Four variables are relevant for analyzing subjects' behaviors. The variable "success" is a dummy variable equal to 1 for correct decisions. Subjects have a $67.3 \%$ success rate validating the pre-task calibration (targeted value $71 \%$ ). The variable "hit" is equal to success for signal trials while "false alarm" is a dummy variable equal to 1 for errors in noise trials. The last variable of interest is the response time. We measure the response time as the time between the beginning of the stimulus display (lasting $900 \mathrm{~ms}$ ) and the decision.

Independent variables - To explain these behaviors, we use three different types of variables. For each treatment we add an indicative variable (Symmetric, Low Gain, High Gain, and Loss) to estimate the impact of treatments on behavior . The second set of variables is given by individual characteristics (gender, age and attitudes toward risk, loss and ambiguity). Finally, we control for trials number within each treatment.

Results: weak supports for Hypothesis 1.1 and Hypothesis 1.2 - The treatment variable is relevant in explaining the four independent variables (Fisher test; p-value: hit $=0.081$, false alarm $=0.032$, success $=0.086$ and reaction times $<0.001)$. As predicted by Hypothesis 1.1 and Hypothesis 1.2, successes are positively affected by the Symmetric Treatment. Interestingly the effect is driven by the false alarm rate but not by the hit rate. It means that individuals, in the symmetric treatment, were performing better in noise trials without decreasing their performance in signal trials. The Low Gain Treatment is associated with more successes however the effect is this time driven by the hit rate. This low gain framework may involve less pressure on participants as all digits are lower.

Result: no support for Hypothesis 1.4 - The Loss Treatment has no influence on the decision outcomes (Fisher test; p-values: hit $=0.345$, false alarm $=0.756$ and success $=$ 0.695). ${ }^{18}$ However in the Loss Treatment, subjects took more time to make their decisions (Fisher test, $\mathrm{p}$-value $=0.006)$. It is in line with previous research that has suggested that

\footnotetext{
${ }^{17}$ Effects are estimated with and without control variables.

${ }^{18}$ This result is robust when reducing the analysis to only asymmetric treatments.
} 
polarity and numerical magnitudes of negative numbers are represented separately and thus associated with higher response times (Tzelgov et al., 2009; Blair et al., 2012).

Additional results - Analyzing attitudes toward risk, loss and ambiguity, we note that only loss attitude under ambiguity explains performances. Subjects exhibiting loss aversion under ambiguity have a lower false alarm rate and a higher success rate while loss seeking subjects have a lower hit rate. These better performances have been achieved as a result of higher response times.

It raises the question: does loss aversion (under ambiguity) induce different behaviors in the Loss Treatment? The cross effect of the Loss Treatment and loss attitude under ambiguity has a significant influence on the false alarms (Fisher test, p-value $=0.038$ ), successes (Fisher test, p-value $=0.069$ ) and response times (Fisher test, p-value: 0.029). Being loss averse (under ambiguity) increases response times more in the Loss Treatment. Being loss seeker (under ambiguity) decreases the success rate by more in this treatment (SI Table 3). We conclude that when subjects are loss averse under ambiguity and confronted to loss, ambiguity or both, they invest more cognitive resources in the task and also achieve higher performances. The fact that attitudes toward ambiguity are significant while attitudes toward risk are not is in line with the empirical differentiation of attitudes toward risk and ambiguity (Cohen et al., 2011). Finally, we do not observe a learning effect during the experiment as the trial number has no effect on decisions. The significant negative trend on response times could be explained by the additional time needed by subjects to get used to the new payoff matrix in the first trials of each treatment.

\subsubsection{SDT-based analysis}

This subsection studies the three SDT-based hypotheses: Hypothesis 1.1, Hypothesis 1.2 and Hypothesis 1.3. To conclude, we oppose asymmetric treatments (trade-off existence) to the symmetric treatment (trade-off absence). We first provide an analysis of the distribution of SDT estimates, then analyze SDT predictions at a subject-treatment level and at a decision level.

\section{SDT estimates}

Level of analysis and SDT specification - The strength of SDT relies on ability to disentangle the impact of the task difficulty from the decision rules. In theory the task difficulty is the same for all treatments. Empirically, effort, learning, tiredness or some other random components of the decision process may induce differences in the subjects' capacity to discriminate. As the estimation of criteria relies on estimations of discrimination, if variations in discrimination are not totally random it may affect the quality of the criteria's estimations. In order to control for these variations, we compute criteria and discrimination for each subject and each treatment. Parameters are estimated by 


\begin{tabular}{|c|c|c|c|c|c|c|c|c|}
\hline & \multicolumn{8}{|c|}{ Dependent variable: } \\
\hline & \multicolumn{2}{|c|}{ Hit } & \multicolumn{2}{|c|}{ False Alarm } & \multicolumn{2}{|c|}{ Success } & \multicolumn{2}{|c|}{ Response time } \\
\hline & $(1)$ & $(2)$ & $(3)$ & $(4)$ & $(5)$ & $(6)$ & $(7)$ & $(8)$ \\
\hline \multicolumn{9}{|l|}{ Treatments } \\
\hline Symmetric & $\begin{array}{c}0.00001 \\
(0.103)\end{array}$ & $\begin{array}{l}0.0001 \\
(0.103)\end{array}$ & $\begin{array}{c}-0.279^{* * *} \\
(0.095)\end{array}$ & $\begin{array}{c}-0.280^{* * *} \\
(0.095)\end{array}$ & $\begin{array}{c}0.144^{* *} \\
(0.068)\end{array}$ & $\begin{array}{l}0.144^{* *} \\
(0.068)\end{array}$ & $\begin{array}{c}0.068^{*} \\
(0.038)\end{array}$ & $\begin{array}{l}0.068^{*} \\
(0.038)\end{array}$ \\
\hline Low Gain & $\begin{array}{c}0.221^{* *} \\
(0.105)\end{array}$ & $\begin{array}{c}0.221^{* *} \\
(0.105)\end{array}$ & $\begin{array}{l}-0.115 \\
(0.094)\end{array}$ & $\begin{array}{l}-0.115 \\
(0.094)\end{array}$ & $\begin{array}{c}0.154^{* *} \\
(0.068)\end{array}$ & $\begin{array}{c}0.154^{* *} \\
(0.068)\end{array}$ & $\begin{array}{c}0.002 \\
(0.038)\end{array}$ & $\begin{array}{c}0.002 \\
(0.038)\end{array}$ \\
\hline Loss & $\begin{array}{c}0.152 \\
(0.104)\end{array}$ & $\begin{array}{c}0.153 \\
(0.104)\end{array}$ & $\begin{array}{l}-0.106 \\
(0.094)\end{array}$ & $\begin{array}{l}-0.106 \\
(0.094)\end{array}$ & $\begin{array}{c}0.121^{*} \\
(0.068)\end{array}$ & $\begin{array}{c}0.121^{*} \\
(0.068)\end{array}$ & $\begin{array}{c}0.147^{* * *} \\
(0.038)\end{array}$ & $\begin{array}{c}0.147^{* * *} \\
(0.038)\end{array}$ \\
\hline \multicolumn{9}{|l|}{ Individual Characteristics } \\
\hline Loss Averse Under Risk & & $\begin{array}{l}-0.015 \\
(0.256)\end{array}$ & & $\begin{array}{c}0.021 \\
(0.228)\end{array}$ & & $\begin{array}{l}-0.024 \\
(0.199)\end{array}$ & & $\begin{array}{c}0.053 \\
(0.167)\end{array}$ \\
\hline Loss Seeker Under Risk & & $\begin{array}{c}0.266 \\
(0.319)\end{array}$ & & $\begin{array}{c}0.421 \\
(0.283)\end{array}$ & & $\begin{array}{l}-0.106 \\
(0.246)\end{array}$ & & $\begin{array}{c}0.184 \\
(0.206)\end{array}$ \\
\hline Loss Averse Under Ambiguity & & $\begin{array}{c}0.409 \\
(0.299)\end{array}$ & & $\begin{array}{c}-0.578^{* *} \\
(0.266)\end{array}$ & & $\begin{array}{l}0.502^{* *} \\
(0.232)\end{array}$ & & $\begin{array}{c}0.258 \\
(0.194)\end{array}$ \\
\hline Loss Seeker Under Ambiguity & & $\begin{array}{l}-0.553 \\
(0.383)\end{array}$ & & $\begin{array}{c}0.173 \\
(0.344)\end{array}$ & & $\begin{array}{l}-0.313 \\
(0.299)\end{array}$ & & $\begin{array}{c}0.315 \\
(0.252)\end{array}$ \\
\hline Ambiguity Averse Under Gain & & $\begin{array}{l}-0.128 \\
(0.297)\end{array}$ & & $\begin{array}{c}0.084 \\
(0.266)\end{array}$ & & $\begin{array}{l}-0.084 \\
(0.231)\end{array}$ & & $\begin{array}{l}-0.274 \\
(0.194)\end{array}$ \\
\hline Ambiguity Seeker Under Gain & & $\begin{array}{l}-0.212 \\
(0.292)\end{array}$ & & $\begin{array}{l}-0.064 \\
(0.260)\end{array}$ & & $\begin{array}{l}-0.057 \\
(0.226)\end{array}$ & & $\begin{array}{l}-0.267 \\
(0.189)\end{array}$ \\
\hline Ambiguity Averse Under Loss & & $\begin{array}{c}0.117 \\
(0.253)\end{array}$ & & $\begin{array}{l}-0.219 \\
(0.226)\end{array}$ & & $\begin{array}{c}0.165 \\
(0.196)\end{array}$ & & $\begin{array}{c}0.175 \\
(0.165)\end{array}$ \\
\hline Ambiguity Seeker Under Loss & & $\begin{array}{c}0.430 \\
(0.319)\end{array}$ & & $\begin{array}{l}-0.072 \\
(0.280)\end{array}$ & & $\begin{array}{c}0.214 \\
(0.244)\end{array}$ & & $\begin{array}{l}-0.039 \\
(0.204)\end{array}$ \\
\hline Male & & $\begin{array}{c}0.603^{* * *} \\
(0.215)\end{array}$ & & $\begin{array}{l}-0.018 \\
(0.192)\end{array}$ & & $\begin{array}{c}0.291^{*} \\
(0.167)\end{array}$ & & $\begin{array}{l}-0.101 \\
(0.139)\end{array}$ \\
\hline Age & & $\begin{array}{c}-0.058^{* * *} \\
(0.021)\end{array}$ & & $\begin{array}{c}0.018 \\
(0.019)\end{array}$ & & $\begin{array}{c}-0.036^{* *} \\
(0.017)\end{array}$ & & $\begin{array}{c}0.006 \\
(0.014)\end{array}$ \\
\hline \multicolumn{9}{|l|}{ Other } \\
\hline Trial Number & & $\begin{array}{l}-0.001 \\
(0.003)\end{array}$ & & $\begin{array}{l}0.0005 \\
(0.002)\end{array}$ & & $\begin{array}{c}0.001 \\
(0.002)\end{array}$ & & $\begin{array}{c}-0.004^{* * *} \\
(0.001)\end{array}$ \\
\hline Constant & $\begin{array}{c}1.067^{* * *} \\
(0.140)\end{array}$ & $\begin{array}{c}1.885^{* * *} \\
(0.562)\end{array}$ & $\begin{array}{c}-0.364^{* * *} \\
(0.121)\end{array}$ & $\begin{array}{l}-0.465 \\
(0.503)\end{array}$ & $\begin{array}{c}0.680^{* * *} \\
(0.101)\end{array}$ & $\begin{array}{l}1.049^{* *} \\
(0.435)\end{array}$ & $\begin{array}{c}1.547^{* * *} \\
(0.066)\end{array}$ & $\begin{array}{c}1.475^{* * *} \\
(0.364)\end{array}$ \\
\hline Observations & 4,100 & 4,100 & 4,100 & 4,100 & 8,200 & 8,200 & 8,200 & 8,200 \\
\hline $\mathrm{BIC}$ & 4,507 & 4,580 & 5,248 & 5,323 & 10,025 & 10,107 & 26,563 & 26,666 \\
\hline
\end{tabular}

Table 5: Experiment 1 - SDT-free impacts of treatments, individual characteristics and trial number.

Reading note: Regression - random-effect models logistic (1,2,3,4,5,6) and Gaussian (7,8). Reference groups - High Gain for treatment, "neutral preferences" for preferences variables.

maximum-likelihood using the Gaussian specification of SDT and constraining parameters on their definition set $\left(d^{\prime} \in \mathbb{R}^{+}\right)$. This methodology is reproduced in all SDT-based analyses.

Results - Discriminations and criteria medians are lower for asymmetric treatments (Figure 4). However, we are unable to reject the hypothesis of equality between asymmetric and symmetric treatments for discriminations $(\mathrm{p}$-value $=0.813)$ and criteria $(\mathrm{p}$-value $=0.402) \cdot{ }^{19}$

The direct analysis of criteria and discriminations does not allow us to conclude on

\footnotetext{
${ }^{19}$ Throughout the paper, statistical tests used to compared two samples are two-sided Wilcoxon signed rank tests unless specified otherwise.
} 

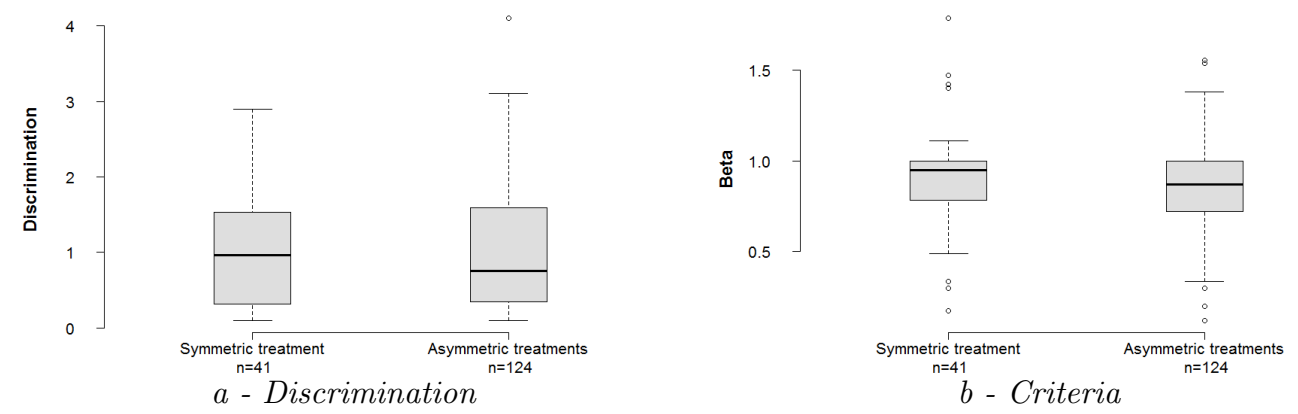

Figure 4: Experiment 1 - Estimated discriminations and criteria.

Reading note: (a) - distribution of the estimated discrimination (a) and $\beta$ criteria (b) for symmetric and asymmetric treatments. Interquartile ranges are represented by the horizontal lines.

Hypothesis 1.1, Hypothesis 1.2 or Hypothesis 1.3. This lack of direct results may come from different factors. First, this approach is conservative as by aggregating information we decrease substantially our statistical power. Second, we do not use the full potential of SDT as we do not take into account its predictive power concerning accuracy maximization or optimality. To better understand the optimality-accuracy trade-off, we provide a comparison of SDT predictions and observed data.

\section{Comparison to SDT predictions at a subject-treatment level}

Level of analysis and specification - We first compute predictions of success rates and payoffs for an accuracy-maximizing and an optimal decision strategy at a subjecttreatment level. We then compute mean ratios between these predictions and observed data. In addition, we tackle the question of a potential efficiency loss due to the optimalityaccuracy trade-off. Results are summarized in Figure 5.

Result: support for Hypothesis 1.1 - Facing the optimality-accuracy trade-off, the observed success rate is $7.9 \%$ higher than the optimal success rate (p-value $<0.001$ ). It induces a payoff decrease of $11.8 \%$ (p-value $<0.001$ ). ${ }^{20}$ Opposing the deviations from predictions in symmetric and asymmetric treatments we observe that subjects are closer to optimality in the Symmetric Treatment for both the success rate and payoffs (p-values < 0.001). We thus conclude that, compared to optimal behaviors, subjects are over-accurate leading to an efficiency loss.

Result: support for Hypothesis 1.2 - For asymmetric payoff matrices, the observed success rate is $1.8 \%$ lower than the accuracy-maximizing success rate (p-values $<0.001$ ). This deviation from the accuracy-maximizing decision strategy induces a $3.9 \%$ increase of subjects' payoffs (p-values $<0.001)$. Again subjects are closer to predictions for payoffs when there is no trade-off ( $\mathrm{p}$-value $<0.001)$. Concerning success rates the difference is

\footnotetext{
${ }^{20}$ To control for the differences in performance-based payoffs from one treatment to another, we scale the payoffs by subtracting the minimal payoff (i.e. payoff for errors) from the actual payoff.
} 


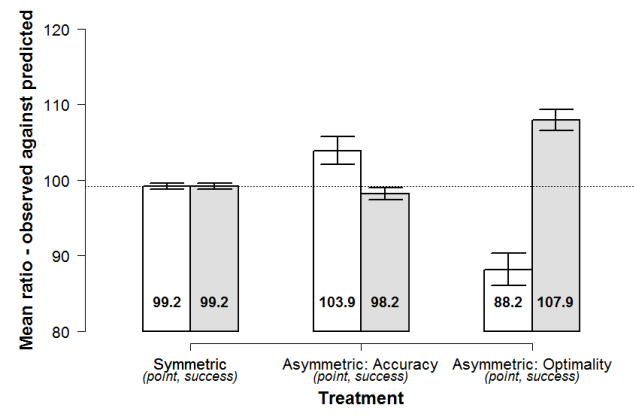

Figure 5: Deviations from accuracy-maximizing and optimal decision strategies.

Reading note: the mean ratio between observed and predicted decisions for the symmetric treatment and the asymmetric treatments are represented. White bars provide points comparisons and grey bars provide success rate comparisons. 95\% confidence intervals are represented by the horizontal lines. By construction, deviations expressed in term of points and success rate are equal for the Symmetric Treatment.

not significant $(\mathrm{p}$-value $=0.156)$. These analyses globally support that subjects deviate from the accuracy-maximizing strategy toward the optimal strategy.

Result: support for Hypothesis 1.3 - Subjects are neither pure accuracy-maximizer nor optimal, however from which behavior do they differ the less? We observe that deviations from accuracy maximization are weaker than the deviations from optimality both in term of success rate and payoffs (p-values $<0.001)$.

\section{Comparison to SDT predictions at a decision level}

We assess if previous findings are reproduced at a decision level. We also investigate if SDT predictions are relevant in explaining data. Table 6 presents results for the four predicted variables based on the accuracy-maximizing criterion and the optimal criterion. ${ }^{21}$

Level of analysis and specification - At a decision level, we test the predicted variables against the observed data including an indicative variable equal to one for asymmetric treatments and a constant $(c)$.

$$
y_{\text {obs }} \sim y_{\text {pred }}+\mathbb{1}_{\{\text {asymmetrictreatment }\}}+c
$$

The dummy variable tells us whether there is an overestimation or an underestimation of the dependent variable for asymmetric treatments. ${ }^{22}$ The significance of the prediction term assesses the relevance of SDT predictions.

Result: support for Hypothesis 1.1 - For asymmetric treatments optimality-based predictions overestimate the hit rate, the false alarm rate and payoffs. They underestimate the success rate. This over-accuracy ultimately results in sub-optimality.

\footnotetext{
${ }^{21}$ All previous analysis are robust when adding controls in the regressions (SI Table 5)

${ }^{22}$ Including a second dummy variable equal to one for the Loss Treatment enables us to test if the rejection of Hypothesis 1.4 is confirmed by SDT-based analysis. For the eight model estimated this dummy variable has no impact on the dependant variable (SI Table 4). It confirms previous findings.
} 
Result: support for Hypothesis 1.2 - Accuracy-based predictions underestimate the number of hits, false alarms and payoffs for asymmetric treatments. It means that subjects are not pure-accuracy maximizers; they are inclined to sacrifice some accuracy for the low stakes trials to increase their accuracy for high stakes trials.

Result: support for Hypothesis 1.3 - By comparing BIC between both predictions rules, we notice that accuracy-based predictions systematically give a better fit to observed data. Thus data reveal an actual criterion closer to the accuracy-maximizing one rather than the optimal one.

Additional result - Each prediction has a positive impact on its corresponding predicted variable at a $1 \%$ test level. Thus predictions are relevant in predicting observed data.

\begin{tabular}{|c|c|c|c|c|c|c|c|c|}
\hline & \multicolumn{8}{|c|}{ Dependent variable: } \\
\hline & \multicolumn{2}{|c|}{ Hit } & \multicolumn{2}{|c|}{ False Alarm } & \multicolumn{2}{|c|}{ Success } & \multicolumn{2}{|c|}{ Payoff } \\
\hline & $(1)$ & $(2)$ & (3) & $(4)$ & (5) & (6) & (7) & $(8)$ \\
\hline Hit Optimal & $\begin{array}{l}1.303^{* *} \\
(0.651)\end{array}$ & & & & & & & \\
\hline Hit Accuracy & & $\begin{array}{c}5.472^{* * *} \\
(0.478)\end{array}$ & & & & & & \\
\hline False Alarm Optimal & & & $\begin{array}{c}2.283^{* * *} \\
(0.198)\end{array}$ & & & & & \\
\hline False Alarm Accuracy & & & & $\begin{array}{c}5.368^{* * *} \\
(0.416)\end{array}$ & & & & \\
\hline Success Optimal & & & & & $\begin{array}{c}4.960^{* * *} \\
(0.212)\end{array}$ & & & \\
\hline Success Accuracy & & & & & & $\begin{array}{c}5.216^{* * *} \\
(0.217)\end{array}$ & & \\
\hline Payoff Optimal & & & & & & & $\begin{array}{c}0.995^{* * *} \\
(0.005)\end{array}$ & \\
\hline Payoff Accuracy & & & & & & & & $\begin{array}{c}0.999^{* * *} \\
(0.005)\end{array}$ \\
\hline Asymmetric & $\begin{array}{l}-0.283 \\
(0.221)\end{array}$ & $\begin{array}{l}0.184^{* *} \\
(0.085)\end{array}$ & $\begin{array}{c}-0.766^{* * *} \\
(0.116)\end{array}$ & $\begin{array}{l}0.178^{* *} \\
(0.079)\end{array}$ & $\begin{array}{c}0.284^{* * *} \\
(0.059)\end{array}$ & $\begin{array}{l}-0.013 \\
(0.057)\end{array}$ & $\begin{array}{c}-0.498^{* * *} \\
(0.091)\end{array}$ & $\begin{array}{l}0.185^{* *} \\
(0.090)\end{array}$ \\
\hline Constant & $\begin{array}{c}0.202 \\
(0.452)\end{array}$ & $\begin{array}{c}-2.697^{* * *} \\
(0.336)\end{array}$ & $\begin{array}{c}-1.339^{* * *} \\
(0.109)\end{array}$ & $\begin{array}{c}-2.342^{* * *} \\
(0.160)\end{array}$ & $\begin{array}{c}-2.585^{* * *} \\
(0.149)\end{array}$ & $\begin{array}{c}-2.754^{* * *} \\
(0.151)\end{array}$ & $\begin{array}{l}-0.009 \\
(0.089)\end{array}$ & $\begin{array}{l}-0.029 \\
(0.082)\end{array}$ \\
\hline Observations & 4,100 & 4,100 & 4,100 & 4,100 & 8,200 & 8,200 & 8,200 & 8,200 \\
\hline $\mathrm{BIC}$ & 4,499 & 4,399 & 5,125 & 5,104 & 9,758 & 9,741 & 44,124 & 44,052 \\
\hline
\end{tabular}

Table 6: Experiment 1 - Impacts of SDT predictions on observed behaviors.

Reading note: for each dependent variable, we present the causal effect of the corresponding predicted variable based on either optimal decision (odd numbers) or accuracy-maximizing (even numbers) strategies. Regressions estimate random-effect models logistic (1,2,3,4,5,6) and Gaussian (7,8).

\subsubsection{Attitudes toward risk}

The utility-maximizing criterion - We defined optimality as the strategy aiming to maximize the expected value of the decision. But individuals may evaluate the payoffs matrices in terms of expected utility instead. As our design involves equal base-rates, there is no effect of weighted probabilities. Likewise, as our asymmetrical rewards are in gains or 
losses but not in mixed outcomes, we do not have an effect of loss aversion on the optimal criterion. Thus, all changes will come from the shapes of the utility functions under gains and losses. Based on a CRRA utility function, it is possible to define another criterion than the standard optimal criterion: the SDT criterion maximizing expected utility. This criterion is obtained like the optimal decision criterion (cf. Equation 3) with the difference that the utility of payoffs replaces their actual values. It is thus defined by:

$$
\beta_{U}^{*}=\frac{U(\Pi(\text { correct rejection }))-U(\Pi(\text { false alarm }))}{U(\Pi(\text { hit }))-U(\Pi(\text { miss }))}
$$

with $U$ the CRRA utility function (cf. Equation 8 and Equation 9).

Assuming risk aversion in the gain domain the new utility-maximizing criterion will be higher than the optimal criterion for positive asymmetrical rewards. On the contrary, assuming risk seeking in the loss domain the utility-maximizing criterion will be lower than the optimal one for the negative payoffs. we assess the robustness of Hypothesis 1.1 and Hypothesis 1.3 using utility-maximizing decision criteria based on individual estimations of risk preferences. ${ }^{23}$

Estimation - The estimated $\beta_{U}^{*}$ have a mean of $0.530(s . d .=0.280)$ for the Low Gain Treatment, a mean of $0.386(s . d .=0.086)$ for the High Gain Treatment and a mean of $0.234(s . d .=0.185)$ for the Loss Treatment. By definition, utility-maximizing criteria are equal to the optimal criterion for the Symmetric Treatment $\left(\beta_{U}^{*}=1\right)$.

Result: Hypothesis 1.1 is also supported for the utility-maximizing decision criterion SDT predictions at a subject-treatment level highlight that the observed success rate is $8.8 \%$ higher than the utility-maximizing success rate $(p-$ value $<0.001)$ for asymmetric treatments. It implies a payoff decrease of $10.30 \%(p-$ value $=0.011)$. SDT predictions at a decision level reveal that utility-maximizing predictions also lead subjects to overestimate the hit rate, the false alarm rate and the payoffs while underestimating the success rate (SI Table 6).

Result: Hypothesis 1.3 is also supported for the utility-maximizing decision criterion - Deviations from accuracy maximization are lower than the deviations from utility maximization both in term of success rate and payoffs (p-values: success $<0.001$ and payoff $<0.001)$.

Additional result - By comparing BIC of SI Table 6 and Table 6 , we notice that utilitymaximizing predictions have an lower predictive power than optimality based predictions. It gives support to the payoff-maximization approach.

\footnotetext{
${ }^{23}$ In SI D.2, we detail our methodology of estimation. In addition, we show in SI D.3 that our results will hold using highly conservative estimations of utility-maximizing criteria.
} 


\subsection{Results - Experiment 2}

Experiment 2 tackles the question summarized in Hypothesis 2.1: does the value of being right contribute to the observed optimality-accuracy trade-off? The answers lies in the difference of behaviors between the Incentivized Treatment and the Flat Treatment. If subjects are pure-payoff maximizers their decisions should approach random guesses in the Flat Treatment. Otherwise, they should use comparable decision strategies in both treatments. In line with the progression undertaken to investigate Experiment 1 results, Experiment 2 results are first assessed on a SDT-free base before estimating the quality of SDT predictions at a subject-treatment level and finally at a decision level.

\subsubsection{SDT-free analysis at a decision level}

Level of analysis and specification - We regress the treatment and controls on hits, false alarms, successes and response times. Control variables are the trial number, the gender and the age of participants. ${ }^{24}$ Results are given in Table 7 , additional descriptive statistics are to be found in SI Table 2.

Result: subjects outperform random guesses but still decrease their success rate in the Flat Treatment - In the Flat Treatment subjects' success rates decrease. This result is driven both by a decreasing hit rate and an increasing false alarm rate. On average, the success rate decreases from $68.4 \%$ to $63.8 \%$ ( $\mathrm{p}$-value $=0.001)$. We reject the hypothesis that the true mean success rate in the Flat Treatment is equal to $50 \%$ at all common test levels (binomial-test, p-value $<0.001$ ).

Result: response times decrease in the Flat Treatment - Individuals make their decisions more quickly in the Flat Treatment compared to the Incentivized Treatment (p-value $=0.007)$. It confirms that they are sensitive to change in payoff matrices. In addition, as in Experiment 1 individuals' response times decrease along treatments.

Conclusion: support for Hypothesis 2.1 - Subjects have on average outperformed random guesses. Thus we cannot find evidence for a pure-payoff maximization. However their accuracy has decreased from the Incentivized Treatment to the Flat Treatment. It shows that when the monetary reward is withdrawn from the value of being right, this value is not strong enough to induce, by itself, the same level of cognitive investment. It is confirmed by the analysis of response times. Based on these considerations, it is not possible to reject Hypothesis 2.1 as subjects are involved in an accuracy-seeking behavior in the Flat Treatment.

\footnotetext{
${ }^{24}$ Two participants entered an inconsistent age $(<3)$, we assigned them the mean age of all other participants.
} 


\begin{tabular}{|c|c|c|c|c|c|c|c|c|}
\hline & \multicolumn{8}{|c|}{ Dependent variable: } \\
\hline & \multicolumn{2}{|c|}{ Hit } & \multicolumn{2}{|c|}{ False Alarm } & \multicolumn{2}{|c|}{ Success } & \multicolumn{2}{|c|}{ Response Time } \\
\hline & (1) & $(2)$ & (3) & (4) & $(5)$ & (6) & $(7)$ & (8) \\
\hline \multicolumn{9}{|l|}{ Treatments } \\
\hline Flat Treatment & $\begin{array}{c}-0.215^{* *} \\
(0.098)\end{array}$ & $\begin{array}{c}-0.215^{* *} \\
(0.098)\end{array}$ & $\begin{array}{l}0.231^{* *} \\
(0.092)\end{array}$ & $\begin{array}{c}0.231^{* *} \\
(0.092)\end{array}$ & $\begin{array}{c}-0.218^{* * *} \\
(0.066)\end{array}$ & $\begin{array}{c}-0.218^{* * *} \\
(0.066)\end{array}$ & $\begin{array}{c}-0.218^{* * *} \\
(0.022)\end{array}$ & $\begin{array}{c}-0.218^{* * *} \\
(0.022)\end{array}$ \\
\hline \multicolumn{9}{|l|}{ Controls } \\
\hline Trial number & & $\begin{array}{l}-0.004 \\
(0.004)\end{array}$ & & $\begin{array}{l}-0.001 \\
(0.003)\end{array}$ & & $\begin{array}{c}-0.0001 \\
(0.002)\end{array}$ & & $\begin{array}{c}-0.005^{* * *} \\
(0.001)\end{array}$ \\
\hline Male & & $\begin{array}{l}-0.211 \\
(0.268)\end{array}$ & & $\begin{array}{l}-0.135 \\
(0.173)\end{array}$ & & $\begin{array}{l}-0.022 \\
(0.172)\end{array}$ & & $\begin{array}{c}0.013 \\
(0.121)\end{array}$ \\
\hline Age & & $\begin{array}{l}0.0001 \\
(0.027)\end{array}$ & & $\begin{array}{l}-0.001 \\
(0.017)\end{array}$ & & $\begin{array}{c}0.001 \\
(0.017)\end{array}$ & & $\begin{array}{l}-0.009 \\
(0.012)\end{array}$ \\
\hline Constant & $\begin{array}{c}1.001^{* * *} \\
(0.137)\end{array}$ & $\begin{array}{l}1.226^{*} \\
(0.699)\end{array}$ & $\begin{array}{c}-0.694^{* * *} \\
(0.094)\end{array}$ & $\begin{array}{l}-0.571 \\
(0.460)\end{array}$ & $\begin{array}{c}0.816^{* * *} \\
(0.087)\end{array}$ & $\begin{array}{l}0.812^{*} \\
(0.449)\end{array}$ & $\begin{array}{c}1.730^{* * *} \\
(0.057)\end{array}$ & $\begin{array}{c}2.064^{* * *} \\
(0.314)\end{array}$ \\
\hline Observations & 2,150 & 2,150 & 2,150 & 2,150 & 4,300 & 4,300 & 4,300 & 4,300 \\
\hline $\mathrm{BIC}$ & 2,561 & 2,582 & 2,797 & 2,819 & 5,400 & $5,425.222$ & 9,549 & 9,553 \\
\hline
\end{tabular}

Table 7: Experiment 2 - SDT-free impacts of the Flat Treatment, demographics and trial number.

\subsubsection{SDT-based analysis}

\section{SDT-based analysis at a cross subject-treatment level}

Level of analysis and specification - Discrimination and decision parameters are computed at a cross subject-treatment level. If subjects were only maximizing rewards, their discrimination should be close to null and their decision criteria should approach a random distribution.

Results: decision criteria are not different between treatments and do not reflect randomguesses - We cannot reject the equality of criteria between treatments ( -value $=0.491$ ). In the Flat Treatment we notice much more extreme values than in the Incentivized Treatment; however more values are gathered around the median (Figure 6 - b). Using a Levene's test for equality of variance (Levene, 1960), we accept the treatments variance equality hypothesis ( $\mathrm{p}$-value $=0.718)$. We test criteria distribution using KolmogorovSmirnov tests. First, we compared criteria from both treatments. We do not reject the hypothesis of equal distribution at all common test levels ( $\mathrm{p}$-value $=0.303$ ). Then, we test criteria from the Flat Treatment against a uniform distribution of same range. We reject the hypothesis of equal distribution at $1 \%$ (p-value $<0.001$ ).

Result: discriminations decrease in the Flat Treatment but stay above null discrimination - The discrimination is lower in the Flat Treatment ( $p$-value $<0.001$, Figure 6 - a). The number of subjects with a null discrimination increases by one from the Incentivized to the Flat Treatment (14\% against $16 \%$ of $\left.\hat{d}^{\prime}\right)$.

Conclusion: support for Hypothesis 2.1 - Once again, SDT enables us to disentangle the decision strategy from the discrimination. We find no difference in decisions strategies 

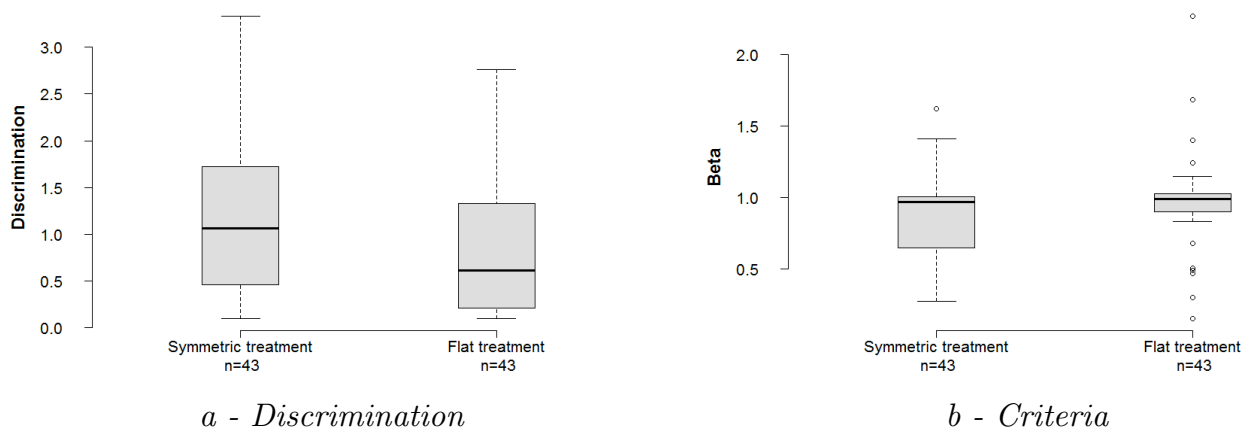

Figure 6: Experiment 2 - Estimated discrimination and criteria.

Reading note: Distribution of the estimated discrimination (a) and $\beta$ criteria (b) for Incentivized and Flat Treatments. Interquartile ranges are represented by the horizontal lines.

between treatments and a non-random strategy for the Flat Treatment. We explain the decreasing discrimination in the Flat Treatment compared to the Incentivized Treatment by a decrease in the effort level. Subjects invested less cognitive resources when monetary rewards were suppressed. However, the value of being right has kept discrimination above a random-guess level. To complete the spectrum of analysis we assess the robustness of previous conclusions at a decision-level analysis.

\section{SDT-based analysis at a decision level}

Level of analysis and specification - We produce decision predictions based on estimated discrimination and theoretical $\beta$. In Experiment 2 only $\beta_{a}=1$ can be used as reference. $^{25}$

Regressions of forecast variables against observed variables are given in Table $8 .{ }^{26} \mathrm{We}$ are mainly interested in studying to which extent the accuracy-maximizing criterion $\left(\beta_{a}\right)$ is relevant for predicting behaviors in the Flat Treatment.

Result: accuracy-maximizing predictions explain behaviors in both treatments with a better fit for the Incentivized Treatment - We notice that all predictions are explaining actual behaviors. In addition, the Flat Treatment variable has no explanatory power. It means that the initial hypothesis made for predicting data $\left(\beta=\beta^{a}\right)$ is relevant to explain data for treatments with and without incentives. Finally, we have computed the quality of fit using BIC by clustering data according to treatments. The Incentivized Treatment is better fitted than the Flat Treatment. ${ }^{27}$

Conclusion: support for Hypothesis 2.1 - Data being explained by accuracy-maximization

\footnotetext{
${ }^{25}$ Under the hypothesis of mixed valuation of optimality and accuracy subjects should use this criterion in both treatments. Under the hypothesis of pure-payoff maximization, it is impossible to compute a unique reference criterion as subjects are supposed to behave randomly.

${ }^{26}$ Predictions are produced for hits, false alarms and successes. Payoffs are not predicted as by definition observed and predicted data are the same for at least half of the sample.

${ }^{27}$ All previously described results are robust to controls (SI Table 7 ).
} 
predictions reinforces previous findings on the role played by the value of being right in the optimality-accuracy trade-off. Higher deviations from predictions in the Flat Treatment are identified consistently with the decreasing level of effort in non-incentivized treatments.

\begin{tabular}{|c|c|c|c|}
\hline & \multicolumn{3}{|c|}{ Dependent variable: } \\
\hline & $\begin{array}{l}\text { Hit } \\
(1)\end{array}$ & $\begin{array}{c}\text { False Alarm } \\
(2)\end{array}$ & $\begin{array}{c}\text { Success } \\
(3)\end{array}$ \\
\hline Predicted Hit & $\begin{array}{c}6.053^{* * *} \\
(0.572)\end{array}$ & & \\
\hline Predicted False Alarm & & $\begin{array}{c}4.016^{* * *} \\
(0.490)\end{array}$ & \\
\hline Predicted Success & & & $\begin{array}{c}4.843^{* * *} \\
(0.306)\end{array}$ \\
\hline Flat Treatment & $\begin{array}{c}0.054 \\
(0.101)\end{array}$ & $\begin{array}{c}0.047 \\
(0.094)\end{array}$ & $\begin{array}{l}0.0005 \\
(0.068)\end{array}$ \\
\hline Constant & $\begin{array}{c}-3.182^{* * *} \\
(0.391)\end{array}$ & $\begin{array}{c}-1.939^{* * *} \\
(0.173)\end{array}$ & $\begin{array}{c}-2.521^{* * *} \\
(0.210)\end{array}$ \\
\hline Observations & 2,150 & 2,150 & 4,300 \\
\hline BIC Flat & 1,318 & 1,410 & 2,727 \\
\hline BIC Incentive & 1,194 & 1,349 & 2,543 \\
\hline
\end{tabular}

Table 8: Experiment 2 - Impacts of SDT predictions on observed behaviors.

Reading note: for each dependent variable, we present the causal effect of the corresponding predicted variable based on the accuracy-maximizing strategy. Regressions estimate logistic random-effect models. AIC correspond to regressions clustered per treatment.

\section{Discussion and Conclusion}

In most circumstances, seeking accuracy is relevant to achieving optimality. However, in a situation with different types of successes and errors rewarded asymmetrically, significant departures from accuracy must be achieved to approach optimality. As a consequence, an optimality-accuracy trade-off arises. Based on a multi-level analysis, the first experiment confirms the existence of the optimality-accuracy trade-off using a signal-in-noise detection task. Actual behaviors exhibit a deviation from accuracy in the direction of optimality but do not approach the optimal solution. This tendency is so pronounced that we observe a leading role of accuracy in the trade-off. ${ }^{28}$ In most of our analysis, we consider that the optimal decision strategy is the strategy maximizing expected payoffs. In addition, we obtain that the optimality-accuracy trade-off is robust to a shift from expected payoff to expected utility by computing individual weighting functions based on CRRA utility. In that sense, we confirm part of Ackermann and Landy (2015) results; however our findings

\footnotetext{
${ }^{28}$ Subjects seem to be aware of this behavior. In a question at the end of Experiment 1, $80 \%$ of them report that they tried to maximize their success rates rather than their payoffs.
} 
mitigate the importance of a utility-based approach. Individual preferences toward risk, ambiguity and loss have a low explanatory power on observed behaviors, while we should observe important effects if subjective utility was playing a key role in the decision process. Moreover, our design allows us to reject the impact of losses on the trade-off. It seems that in this perceptual task, individuals react less to reference-point manipulations than in preferences tasks (e.g. lotteries). This lack of effect is even more remarkable in that we do not implement a loss framing but real monetary losses in the experiment. This result, that extend previous findings based on a mixed gain-loss framework (Maddox et al., 2003b), goes against the relevance of applying the Prospect Theory framework to this context. The second experiment investigates if attitudes toward the optimality-accuracy tradeoff could be impacted by the value of being right. Our approach, based on an original design enabling us to directly tackle this question, provides new insights and contrasts with previous results (Maddox and Bohil, 2003, 2004). In line with the leading role of accuracy, our multi-level evaluation of the value of being right reveals that this value plays a central role in the trade-off solution. When removing all monetary incentives, we obtain that individuals are driven by a search for accuracy.

The role of intrinsic motivations has been highlighted to play a major role in individuals' decisions (Camerer and Hogarth, 1999; Gneezy and Rustichini, 2000). The importance of the value of being right gives evidence that the optimality-accuracy tradeoff may find its foundations in an opposition between intrinsic and extrinsic motivations. Even if individuals are explicitly asked to maximize payoffs, they may intrinsically value to give correct answers. Extrinsic incentives are not aligned with internal motivations for asymmetric incentives as they are maximal when accepting giving more false answers than necessary. This interpretation of the optimality-accuracy trade-off is in line with previous research obtaining that multiplying all payoffs by a constant and thus raising extrinsic incentives for a comparable level of intrinsic incentives leads to decisions closer to optimality (Bohil and Maddox, 2003). This internal valuation of success has been highlighted in other contexts. Thinking about how individuals behave in contests, this same mechanism of induced utility of success has been obtained and referred as the joy of winning (Price and Sheremeta, 2011; Mago et al., 2013). To extend such findings in an individual setting is interesting as this utility is not driven by competition and the seek for out-performing our counterparts but only by internal challenge and self-ego.

To obtain this result, we evaluate the role of intrinsic valuation in a flat payoff setting to cancel extrinsic motivations and thus isolate intrinsic motivations. However, one limitation is that extrinsic and intrinsic motivations may interact. Extrinsic motivation may crow-out intrinsic motivations resulting in a decrease of effort or motivation when payoff incentives are implemented (Gneezy et al., 2011). We find no evidence of such 
mechanism as, in our flat treatment, individuals' response time decreases compared to the Incentivized Treatment. It demonstrates that when suppressing external motivation, the effort level is not increasing. To go a step further in the evaluation of the value of being right, it is possible to oppose extrinsic and intrinsic valuations. For example, rewarding more errors than successes or allowing subjects to observe stimuli again at a cost would induce this opposition. If subjects continue to sacrifice payoffs for accuracy, even in such a salient framework, it would reinforce the importance of the value of being right. Another limitation is that we cannot exclude a potential experimenter demand effect (Zizzo, 2010). The search for accuracy might be linked to an internal pressure for subjects to perform a task in a laboratory setting. While we do not have a control for this effect we doubt that it drives our result. First, subjects performed the Incentivized Treatment and the Flat Treatment in a same session. This should decrease the pressure felt by subjects to perform the non-incentivized task by comparison of both treatments. We also argue that real-life situations are quite similar with internal or external pressure to succeed even without rewards. Thus, we conclude in favor of our accuracy seeking hypothesis and that individuals intrinsically value the fact of being right.

From a methodological point of view, this paper argues in favor of the use of SDT to analyze our research question. This computational approach is widely used in cognitive sciences but still uncommon in economics. We think that understanding the optimality accuracy trade-off requires such a framework. Indeed, our study puts forward the three main aspects of SDT (Wickens, 2001). It provides a powerful tool to analyze the observed behaviors in terms of decision strategies and task properties. It allows for comparison between treatments to precisely identify the impacted aspects of the behaviors. Finally, it defines what is optimality by a modelisation of how an optimal individual should behave. Thus without the use of SDT we would have been unable to define the trade-off and to get insights of its main properties. As what can be considering as a drawback, a SDT analysis implies the use of perceptual decisions. Rather, we believe that it can be a pertinent paradigm for further research in experimental economics. First, it allows for a control of the cognitive processes involved in the decision, while an economic task will always imply a lower control of what the subjects have really in mind. Second, we can argue that our approach of SDT relies on both the perceptual and the economic components of a decision. The optimality accuracy trade-off may be based on the assessment of perceptual information (visual stimuli) and preferences (utility of payoffs). In that sense, a more frequent use of perceptual tasks in experimental economics may allow a combine framework of perceptual and economic decision-making (Summerfield and Tsetsos, 2012; Lynn et al., 2015). Last, a perceptual task is not different from other tasks used in experimental economics, in the sense that they all suffer from artificiality but are relevant 
for the theory tested and necessary to observe and measure the outcomes of interest (Starmer, 1999). For all these reasons we hope that the use of computational models such as SDT will continue to develop in economic studies.

Identifying the optimality-accuracy trade-off and understanding its reasons, as this paper attempts, is a basic prerequisite to change behaviors toward more optimality. In a decision support tool perspective, it opens the question to know how to develop policies to correct the decision process and how to inverse the trade-off in favor of optimal behaviors.

\section{References}

Ackermann, J. F. and Landy, M. S. (2015). Suboptimal decision criteria are predicted by subjectively weighted probabilities and rewards. Attention, Perception, \&S Psychophysics, 77(2):638-658.

Alicke, M. D., Davis, T. L., and Pezzo, M. V. (1994). A posteriori adjustment of a priori decision criteria. Social Cognition, 12(4):281.

Andersen, S., Harrison, G. W., Lau, M. I., and Rutström, E. E. (2008). Eliciting risk and time preferences. Econometrica, 76(3):583-618.

Balci, F., Simen, P., Niyogi, R., Saxe, A., Hughes, J. A., Holmes, P., and Cohen, J. D. (2011). Acquisition of decision making criteria: reward rate ultimately beats accuracy. Attention, Perception, \& Psychophysics, 73(2):640-657.

Barkan, R., Zohar, D., and Erev, I. (1998). Accidents and decision making under uncertainty: A comparison of four models. Organizational behavior and human decision processes, 74(2):118-144.

Baron, J. and Hershey, J. C. (1988). Outcome bias in decision evaluation. Journal of personality and social psychology, 54(4):569.

Blair, K. P., Rosenberg-Lee, M., Tsang, J. M., Schwartz, D. L., and Menon, V. (2012). Beyond natural numbers: negative number representation in parietal cortex. Frontiers in human neuroscience, 6:7.

Bogacz, R., Brown, E., Moehlis, J., Holmes, P., and Cohen, J. D. (2006). The physics of optimal decision making: a formal analysis of models of performance in two-alternative forced-choice tasks. Psychological review, 113(4):700.

Bohil, C. J. and Maddox, W. T. (2001). Category discriminability, base-rate, and payoff effects in perceptual categorization. Attention, Perception $\&$ Psychophysics, 63(2):361376. 
Bohil, C. J. and Maddox, W. T. (2003). On the generality of optimal versus objective classifier feedback effects on decision criterion learning in perceptual categorization. Memory \& Cognition, 31(2):181-198.

Brainard, D. H. (1997). The psychophysics toolbox. Spatial vision, 10:433-436.

Brown, G. S. and White, K. G. (2005). The optimal correction for estimating extreme discriminability. Behavior research methods, 37(3):436-449.

Busemeyer, J. R. and Myung, I. J. (1992). An adaptive approach to human decision making: Learning theory, decision theory, and human performance. Journal of Experimental Psychology: General, 121(2):177.

Camerer, C. F. and Hogarth, R. M. (1999). The effects of financial incentives in experiments: A review and capital-labor-production framework. Journal of Risk and Uncertainty, 19(1):7-42.

Cohen, M., Tallon, J.-M., and Vergnaud, J.-C. (2011). An experimental investigation of imprecision attitude and its relation with risk attitude and impatience. Theory and Decision, 71(1):81-109.

Dai, Z., Galeotti, F., and Villeval, M. C. (2017). Cheating in the lab predicts fraud in the field: An experiment in public transportation. Management Science.

Dave, C., Eckel, C. C., Johnson, C. A., and Rojas, C. (2010). Eliciting risk preferences: When is simple better? Journal of Risk and Uncertainty, 41(3):219-243.

Dohmen, T., Falk, A., Huffman, D., Sunde, U., Schupp, J., and Wagner, G. G. (2011). Individual risk attitudes: Measurement, determinants, and behavioral consequences. Journal of the European Economic Association, 9(3):522-550.

Eckel, C. C. and Grossman, P. J. (2008). Forecasting risk attitudes: An experimental study using actual and forecast gamble choices. Journal of Economic Behavior 8 Organization, 68(1):1-17.

Eckel, C. C., Grossman, P. J., Johnson, C. A., de Oliveira, A. C., Rojas, C., and Wilson, R. K. (2012). School environment and risk preferences: Experimental evidence. Journal of Risk and Uncertainty, 45(3):265-292.

Ell, S. W., Ing, A. D., and Maddox, W. T. (2009). Criterial noise effects on rule-based category learning: The impact of delayed feedback. Attention, Perception, 65 Psychophysics, 71(6):1263-1275. 
Erev, I. (1998). Signal detection by human observers: a cutoff reinforcement learning model of categorization decisions under uncertainty. Psychological review, 105(2):280.

Galanter, E. and Holman, G. L. (1967). Some invariances of the isosensitivity function and their implications for the utility function of money. Journal of Experimental Psychology, $73(3): 333$.

Gino, F., Shu, L. L., and Bazerman, M. H. (2010). Nameless + harmless = blameless: When seemingly irrelevant factors influence judgment of (un)ethical behavior. Organizational Behavior and Human Decision Processes, 111(2):93 - 101.

Gneezy, U., Meier, S., and Rey-Biel, P. (2011). When and why incentives (don't) work to modify behavior. The Journal of Economic Perspectives, 25(4):191-209.

Gneezy, U. and Rustichini, A. (2000). Pay enough or don't pay at all. The Quarterly Journal of Economics, 115(3):791-810.

Gold, J. I. and Shadlen, M. N. (2001). Neural computations that underlie decisions about sensory stimuli. Trends in cognitive sciences, 5(1):10-16.

Gold, J. I. and Shadlen, M. N. (2007). The neural basis of decision making. Annual Review of Neuroscience, 30:535-574.

Green, D. and Swets, J. (1966). Signal detection theory and psychophysics. Los Altos, CA: Peninsula.

Greiner, B. (2015). Subject pool recruitment procedures: organizing experiments with orsee. Journal of the Economic Science Association, 1(1):114-125.

Hautus, M. J. (1995). Corrections for extreme proportions and their biasing effects on estimated values ofd? Behavior Research Methods, Instruments, \&6 Computers, 27(1):4651.

Hollard, G., Massoni, S., and Vergnaud, J.-C. (2016). In search of good probability assessors: an experimental comparison of elicitation rules for confidence judgments. Theory and Decision, 80(3):363-387.

Levene, H. (1960). Robust tests for equality of variances. Contributions to probability and statistics: Essays in honor of Harold Hotelling, 2:278-292.

Levitt, H. (1971). Transformed up-down methods in psychoacoustics. The Journal of the Acoustical society of America, 49(2B):467-477. 
Lynn, S. K. and Barrett, L. F. (2014). Utilizing signal detection theory. Psychological science, 25(9):1663-1673.

Lynn, S. K., Wormwood, J. B., Barrett, L. F., and Quigley, K. S. (2015). Decision making from economic and signal detection perspectives: development of an integrated framework. Frontiers in psychology, 6.

Machina, M. and Viscusi, W. K. (2013). Handbook of the Economics of Risk and Uncertainty. North Holland.

Maddox, W. T., Ashby, F. G., and Bohil, C. J. (2003a). Delayed feedback effects on rule-based and information-integration category learning. Journal of experimental psychology: learning, memory, and cognition, 29(4):650.

Maddox, W. T. and Bohil, C. J. (1998). Base-rate and payoff effects in multidimensional perceptual categorization. Journal of Experimental Psychology: Learning, Memory, and Cognition, 24(6):1459.

Maddox, W. T. and Bohil, C. J. (2001). Feedback effects on cost-benefit learning in perceptual categorization. Memory \& Cognition, 29(4):598-615.

Maddox, W. T. and Bohil, C. J. (2003). A theoretical framework for understanding the simultaneous base-rate and payoff manipulations on decision criterion learning in perceptual categorization. Journal of Experimental Psychology: Learning, Memory, and Cognition, 29(2):307.

Maddox, W. T. and Bohil, C. J. (2004). Probability matching, accuracy maximization, and a test of the optimal classifiers independence assumption in perceptual categorization. Attention, Perception \& Psychophysics, 66(1):104-118.

Maddox, W. T. and Bohil, C. J. (2005). Optimal classifier feedback improves cost-benefit but not base-rate decision criterion learning in perceptual categorization. Memory $\mathscr{E}$ cognition, 33(2):303-319.

Maddox, W. T., Bohil, C. J., and Dodd, J. L. (2003b). Linear transformations of the payoff matrix and decision criterion learning in perceptual categorization. Journal of Experimental Psychology: Learning, Memory, and Cognition, 29(6):1174.

Maddox, W. T. and Dodd, J. L. (2001). On the relation between base-rate and costbenefit learning in simulated medical diagnosis. Journal of Experimental Psychology: Learning, Memory, and Cognition, 27(6):1367. 
Mago, S. D., Sheremeta, R. M., and Yates, A. (2013). Best-of-three contest experiments: Strategic versus psychological momentum. International Journal of Industrial Organization, 31(3):287-296.

Massoni, S., Gajdos, T., and Vergnaud, J.-C. (2014). Confidence measurement in the light of signal detection theory. Frontiers in psychology, 5:1455.

Myung, I. J. and Busemeyer, J. R. (1989). Criterion learning in a deferred decision-making task. The American journal of psychology, 102(2):1-16.

Neyman, J. and Pearson, E. S. (1933). On the problem of the most efficient tests of statistical hypotheses. Philosophical Transactions of the Royal Society of London. Series A, Containing Papers of a Mathematical or Physical Character, 231:289-337.

Price, C. R. and Sheremeta, R. M. (2011). Endowment effects in contests. Economics Letters, 111(3):217-219.

Rahnev, D. and Denison, R. (2017). Suboptimality in perception. bioRxiv, 060194.

Roth, A. E. and Erev, I. (1995). Learning in extensive-form games: Experimental data and simple dynamic models in the intermediate term. Games and economic behavior, 8(1):164-212.

Siegel, S. (1959). Theoretical models of choice and strategy behavior: Stable state behavior in the two-choice uncertain outcome situation. Psychometrika, 24(4):303-316.

Starmer, C. (1999). Experiments in economics: should we trust the dismal scientists in white coats? Journal of Economic Methodology, 6(1):1-30.

Summerfield, C. and Tsetsos, K. (2012). Building bridges between perceptual and economic decision-making: neural and computational mechanisms. Frontiers in neuroscience, 6.

Tversky, A. and Kahneman, D. (1991). Loss aversion in riskless choice: A referencedependent model. The quarterly journal of economics, 106(4):1039-1061.

Tzelgov, J., Ganor-Stern, D., and Maymon-Schreiber, K. (2009). The representation of negative numbers: Exploring the effects of mode of processing and notation. The Quarterly Journal of Experimental Psychology, 62(3):605-624.

Wakker, P. P. (2008). Explaining the characteristics of the power (crra) utility family. Health economics, 17(12):1329-1344. 
Wakker, P. P. (2010). Prospect theory: For risk and ambiguity. Cambridge university press.

Wickens, T. D. (2001). Elementary signal detection theory. Oxford university press.

Wu, G. and Markle, A. B. (2008). An empirical test of gain-loss separability in prospect theory. Management Science, 54(7):1322-1335.

Zizzo, D. J. (2010). Experimenter demand effects in economic experiments. Experimental Economics, 13(1):75-98. 


\section{Supplementary Information}

\section{A Hit and false alarm probabilities}

We demonstrate Equation 6 and Equation 7 . We start by introducing the criterion $\lambda$ such that:

$$
\forall(X, \lambda) \in \mathbb{R}^{2}, D(X, \lambda)= \begin{cases}1 & \text { if } X \geq \lambda \\ 0 & \text { if } X<\lambda\end{cases}
$$

The criterion $\lambda$, we can easily write the probability of hit $\left(P_{H}\right)$ and the probability of false alarm $\left(P_{F A}\right)$ :

$$
\begin{aligned}
P_{H} & =\mathbb{P}\left(X_{s}>\lambda\right)=1-\phi\left(\lambda-d^{\prime}\right) \\
P_{F A} & =\mathbb{P}\left(X_{n}>\lambda\right)=1-\phi(\lambda)
\end{aligned}
$$

Using Equation 2, we can express $\beta$ as a function of $\lambda$ :

$$
\beta=L(\lambda)=\frac{\mathbb{P}(\lambda \mid \Theta=1)}{\mathbb{P}(\lambda \mid \Theta=0)}=\frac{f_{s}(\lambda)}{f_{n}(\lambda)}
$$

Thus:

$$
\begin{aligned}
\log (\beta) & =\log \left(\frac{f_{s}(\lambda)}{f_{n}(\lambda)}\right) \\
& =\log \left(\frac{1}{\sqrt{2 \pi}} \exp \left(-\frac{1}{2}\left(\lambda-d^{\prime}\right)^{2}\right)\right)-\log \left(\frac{1}{\sqrt{2 \pi}} \exp \left(-\frac{1}{2} \lambda\right)^{2}\right) \\
& =d^{\prime}\left(\lambda-\frac{1}{2} d^{\prime}\right)
\end{aligned}
$$

Finally, we express $P_{H}$ and $P_{F A}$ as a function of the criterion $\beta$ :

$$
\begin{gathered}
P_{H}=1-\phi\left(\frac{\log (\beta)}{d^{\prime}}-d^{\prime} / 2\right) \\
P_{F A}=1-\phi\left(\frac{\log (\beta)}{d^{\prime}}+d^{\prime} / 2\right)
\end{gathered}
$$




\section{B Complementary results}

\section{B.1 Descriptive statistics}

\begin{tabular}{lccccc}
\hline \hline Statistic & Treatment & $\begin{array}{c}\text { Mean } \\
\text { (\% or ms) }\end{array}$ & St. Dev. & $\begin{array}{c}\text { Min } \\
\text { (\% or ms) }\end{array}$ & $\begin{array}{c}\text { Max } \\
\text { (\% or ms) }\end{array}$ \\
\hline Hit & $\mathrm{S}$ & 72 & 15.44 & 36 & 100 \\
& $\mathrm{LG}$ & 75.90 & 14.35 & 44 & 100 \\
& $\mathrm{~L}$ & 74.73 & 15.96 & 28 & 100 \\
False Alarm & $\mathrm{HG}$ & 72 & 17.55 & 40 & 100 \\
& $\mathrm{~S}$ & 35.61 & 13.88 & 12 & 68 \\
& $\mathrm{LG}$ & 39.12 & 18.84 & 8 & 100 \\
& $\mathrm{~L}$ & 39.32 & 19.06 & 12 & 100 \\
Success & $\mathrm{HG}$ & 41.66 & 21.11 & 0 & 100 \\
& $\mathrm{~S}$ & 68.20 & 11.86 & 50 & 92 \\
& $\mathrm{LG}$ & 68.39 & 12.30 & 50 & 92 \\
& $\mathrm{~L}$ & 67.71 & 13.43 & 34 & 92 \\
Response Time & $\mathrm{HG}$ & 65.17 & 14.70 & 42 & 100 \\
& $\mathrm{~S}$ & 1.62 & 0.42 & 0.89 & 3.00 \\
& $\mathrm{LG}$ & 1.55 & 0.42 & 0.44 & 2.44 \\
& $\mathrm{~L}$ & 1.69 & 0.61 & 0.37 & 3.95 \\
& $\mathrm{HG}$ & 1.55 & 0.38 & 0.73 & 2.58 \\
\hline
\end{tabular}

Note: $\quad$ Symmetric (S), Low Gain (LG), Loss (L) and High Gain (HG).

Table 1: Study 1 - Descriptive Statistics

Reading note: Each subject represents one observation.

\begin{tabular}{lccccc}
\hline \hline Statistic & Treatment & $\begin{array}{c}\text { Mean } \\
\text { (\% or ms) }\end{array}$ & St. Dev. & $\begin{array}{c}\text { Min } \\
\text { (\% or ms) }\end{array}$ & $\begin{array}{c}\text { Max } \\
\text { (\% or ms) }\end{array}$ \\
\hline Hit & I & 71.00 & 17.16 & 32 & 100 \\
False Alarm & F & 65.95 & 15.53 & 32 & 100 \\
& I & 33.95 & 12.75 & 8 & 56 \\
Success & F & 39.07 & 15.49 & 8 & 92 \\
& I & 68.42 & 12.82 & 42 & 96 \\
Response Time & F & 63.77 & 10.86 & 48 & 88 \\
& I & 1.73 & 0.45 & 1.16 & 3.11 \\
Note: & $\mathrm{F}$ & 1.51 & 0.41 & 0.59 & 2.83 \\
\hline
\end{tabular}

Table 2: Experiment 2 - Descriptive Statistics

Reading note: Each subject represents one observation.

\section{B.2 SDT-free analysis}




\begin{tabular}{|c|c|c|c|c|c|c|c|c|}
\hline & \multicolumn{8}{|c|}{ Dependent variable: } \\
\hline & \multicolumn{2}{|c|}{ Hit } & \multicolumn{2}{|c|}{ False Alarm } & \multicolumn{2}{|c|}{ Success } & \multicolumn{2}{|c|}{ Response time } \\
\hline & $(1)$ & $(2)$ & $(3)$ & $(4)$ & $(5)$ & $(6)$ & $(7)$ & $(8)$ \\
\hline \multicolumn{9}{|l|}{ Cross-variables } \\
\hline Loss $\times$ Loss Averse Under Ambiguity & $\begin{array}{l}-0.211 \\
(0.207)\end{array}$ & $\begin{array}{l}-0.211 \\
(0.207)\end{array}$ & $\begin{array}{l}-0.103 \\
(0.178)\end{array}$ & $\begin{array}{l}-0.103 \\
(0.178)\end{array}$ & $\begin{array}{l}-0.023 \\
(0.131)\end{array}$ & $\begin{array}{l}-0.023 \\
(0.131)\end{array}$ & $\begin{array}{c}0.245^{* * *} \\
(0.072)\end{array}$ & $\begin{array}{c}0.245^{* * *} \\
(0.072)\end{array}$ \\
\hline Loss $\times$ Loss Seeker Under Ambiguity & $\begin{array}{l}-0.346 \\
(0.268)\end{array}$ & $\begin{array}{l}-0.346 \\
(0.268)\end{array}$ & $\begin{array}{l}0.472^{*} \\
(0.248)\end{array}$ & $\begin{array}{l}0.476^{*} \\
(0.248)\end{array}$ & $\begin{array}{c}-0.359^{* *} \\
(0.172)\end{array}$ & $\begin{array}{c}-0.359^{* *} \\
(0.172)\end{array}$ & $\begin{array}{l}-0.019 \\
(0.100)\end{array}$ & $\begin{array}{l}-0.019 \\
(0.100)\end{array}$ \\
\hline \multicolumn{9}{|l|}{ Treatments } \\
\hline Symmetric & $\begin{array}{c}-0.00000 \\
(0.103)\end{array}$ & $\begin{array}{c}0.00003 \\
(0.103)\end{array}$ & $\begin{array}{l}-0.278^{* * *} \\
(0.095)\end{array}$ & $\begin{array}{l}-0.278^{* * *} \\
\quad(0.095)\end{array}$ & $\begin{array}{l}0.144^{* *} \\
(0.068)\end{array}$ & $\begin{array}{l}0.144^{* *} \\
(0.068)\end{array}$ & $\begin{array}{c}0.068^{*} \\
(0.038)\end{array}$ & $\begin{array}{l}0.068^{*} \\
(0.038)\end{array}$ \\
\hline Low Gain & $\begin{array}{l}0.221^{* *} \\
(0.105)\end{array}$ & $\begin{array}{l}0.221^{* *} \\
(0.105)\end{array}$ & $\begin{array}{l}-0.115 \\
(0.094)\end{array}$ & $\begin{array}{l}-0.115 \\
(0.094)\end{array}$ & $\begin{array}{l}0.153^{* *} \\
(0.068)\end{array}$ & $\begin{array}{l}0.153^{* *} \\
(0.068)\end{array}$ & $\begin{array}{c}0.002 \\
(0.038)\end{array}$ & $\begin{array}{l}0.002 \\
(0.038)\end{array}$ \\
\hline Loss & $\begin{array}{l}0.334^{*} \\
(0.183)\end{array}$ & $\begin{array}{l}0.334^{*} \\
(0.183)\end{array}$ & $\begin{array}{l}-0.120 \\
(0.155)\end{array}$ & $\begin{array}{l}-0.120 \\
(0.155)\end{array}$ & $\begin{array}{c}0.194^{*} \\
(0.113)\end{array}$ & $\begin{array}{c}0.194^{*} \\
(0.113)\end{array}$ & $\begin{array}{c}0.006 \\
(0.063)\end{array}$ & $\begin{array}{l}0.006 \\
(0.063)\end{array}$ \\
\hline \multicolumn{9}{|l|}{ Individual Characteristics } \\
\hline Loss Averse Under Ambiguity & $\begin{array}{c}0.002 \\
(0.288)\end{array}$ & $\begin{array}{c}0.459 \\
(0.303)\end{array}$ & $\begin{array}{c}-0.550^{* *} \\
(0.218)\end{array}$ & $\begin{array}{c}-0.552^{* *} \\
(0.270)\end{array}$ & $\begin{array}{c}0.298 \\
(0.199)\end{array}$ & $\begin{array}{l}0.508^{* *} \\
(0.234)\end{array}$ & $\begin{array}{c}0.131 \\
(0.145)\end{array}$ & $\begin{array}{c}0.197 \\
(0.195)\end{array}$ \\
\hline Loss Seeker Under Ambiguity & $\begin{array}{l}-0.447 \\
(0.397)\end{array}$ & $\begin{array}{l}-0.469 \\
(0.389)\end{array}$ & $\begin{array}{l}0.190 \\
(0.303)\end{array}$ & $\begin{array}{c}0.054 \\
(0.350)\end{array}$ & $\begin{array}{l}-0.282 \\
(0.276)\end{array}$ & $\begin{array}{l}-0.222 \\
(0.302)\end{array}$ & $\begin{array}{c}0.180 \\
(0.203)\end{array}$ & $\begin{array}{l}0.320 \\
(0.253)\end{array}$ \\
\hline Loss Averse Under Risk & & $\begin{array}{l}-0.015 \\
(0.256)\end{array}$ & & $\begin{array}{c}0.021 \\
(0.229)\end{array}$ & & $\begin{array}{c}-0.024 \\
(0.199)\end{array}$ & & $\begin{array}{c}0.053 \\
(0.167)\end{array}$ \\
\hline Loss Seeker Under Risk & & $\begin{array}{c}0.265 \\
(0.319)\end{array}$ & & $\begin{array}{c}0.425 \\
(0.283)\end{array}$ & & $\begin{array}{l}-0.107 \\
(0.246)\end{array}$ & & $\begin{array}{c}0.184 \\
(0.206)\end{array}$ \\
\hline Ambiguity Averse Under Gain & & $\begin{array}{l}-0.129 \\
(0.297)\end{array}$ & & $\begin{array}{c}0.084 \\
(0.266)\end{array}$ & & $\begin{array}{l}-0.085 \\
(0.231)\end{array}$ & & $\begin{array}{l}-0.274 \\
(0.194)\end{array}$ \\
\hline Ambiguity Seeker Under Gain & & $\begin{array}{l}-0.213 \\
(0.292)\end{array}$ & & $\begin{array}{l}-0.065 \\
(0.260)\end{array}$ & & $\begin{array}{l}-0.057 \\
(0.226)\end{array}$ & & $\begin{array}{l}-0.267 \\
(0.189)\end{array}$ \\
\hline Ambiguity Averse Under Loss & & $\begin{array}{c}0.117 \\
(0.253)\end{array}$ & & $\begin{array}{l}-0.221 \\
(0.226)\end{array}$ & & $\begin{array}{c}0.165 \\
(0.196)\end{array}$ & & $\begin{array}{c}0.175 \\
(0.165)\end{array}$ \\
\hline Ambiguity Seeker Under Loss & & $\begin{array}{c}0.431 \\
(0.319)\end{array}$ & & $\begin{array}{l}-0.072 \\
(0.281)\end{array}$ & & $\begin{array}{c}0.214 \\
(0.244)\end{array}$ & & $\begin{array}{l}-0.039 \\
(0.204)\end{array}$ \\
\hline Male & & $\begin{array}{c}0.604^{* * *} \\
(0.215)\end{array}$ & & $\begin{array}{l}-0.018 \\
(0.192)\end{array}$ & & $\begin{array}{l}0.291^{*} \\
(0.167)\end{array}$ & & $\begin{array}{l}-0.101 \\
(0.139)\end{array}$ \\
\hline \multirow[t]{2}{*}{ Age } & & $-0.058^{* * *}$ & & 0.018 & & $-0.036^{* *}$ & & 0.006 \\
\hline & & $(0.021)$ & & $(0.019)$ & & $(0.017)$ & & $(0.014)$ \\
\hline \multicolumn{9}{|l|}{ Other } \\
\hline Trial Number & & $\begin{array}{l}-0.001 \\
(0.003)\end{array}$ & & $\begin{array}{l}0.0005 \\
(0.002)\end{array}$ & & $\begin{array}{c}0.001 \\
(0.002)\end{array}$ & & $\begin{array}{c}-0.004^{* * *} \\
(0.001)\end{array}$ \\
\hline Constant & $\begin{array}{c}1.130^{* * *} \\
(0.245)\end{array}$ & $\begin{array}{c}1.843^{* * *} \\
(0.563)\end{array}$ & $\begin{array}{l}-0.069 \\
(0.188)\end{array}$ & $\begin{array}{l}-0.464 \\
(0.505)\end{array}$ & $\begin{array}{c}0.546^{* * *} \\
(0.169)\end{array}$ & $\begin{array}{l}1.031^{* *} \\
(0.437)\end{array}$ & $\begin{array}{c}1.444^{* * * *} \\
(0.122)\end{array}$ & $\begin{array}{c}1.510^{* * * *} \\
(0.364)\end{array}$ \\
\hline Observations & 4,100 & 4,100 & 4,100 & 4,100 & 8,200 & 8,200 & 8,200 & 8,200 \\
\hline BIC & 4,536 & 4,595 & 5,262 & 5,333 & 10,048 & 10,120 & 26,591 & 26,674 \\
\hline
\end{tabular}

Table 3: Impacts of the cross-variable Loss Treatment $\times$ loss attitudes under ambiguity.

Reading note: Regression - random-effect models logistic (1,2,3,4,5,6) and Gaussian (7,8). Reference groups - High Gain for treatment, "neutral preferences" for preferences variables. 


\section{B.3 SDT-based analysis}

\begin{tabular}{|c|c|c|c|c|c|c|c|c|}
\hline & \multicolumn{8}{|c|}{ Dependent variable: } \\
\hline & \multicolumn{2}{|c|}{ Hit } & \multicolumn{2}{|c|}{ False Alarm } & \multicolumn{2}{|c|}{ Success } & \multicolumn{2}{|c|}{ Payoff } \\
\hline & $(1)$ & $(2)$ & (3) & $(4)$ & $(5)$ & $(6)$ & $(7)$ & $(8)$ \\
\hline Hit Optimal & $\begin{array}{l}1.326^{* *} \\
(0.650)\end{array}$ & & & & & & & \\
\hline Hit Accuracy & & $\begin{array}{c}5.417^{* * *} \\
(0.466)\end{array}$ & & & & & & \\
\hline False Alarm Optimal & & & $\begin{array}{c}2.345^{* * *} \\
(0.196)\end{array}$ & & & & & \\
\hline False Alarm Accuracy & & & & $\begin{array}{c}5.508^{* * *} \\
(0.401)\end{array}$ & & & & \\
\hline Success Optimal & & & & & $\begin{array}{c}4.960^{* * *} \\
(0.212)\end{array}$ & & & \\
\hline Success Accuracy & & & & & & $\begin{array}{c}5.216^{* * *} \\
(0.217)\end{array}$ & & \\
\hline Payoff Optimal & & & & & & & $\begin{array}{c}0.994^{* * * *} \\
(0.005)\end{array}$ & \\
\hline Payoff Accuracy & & & & & & & & $\begin{array}{r}0.999 * * * \\
(0.005)\end{array}$ \\
\hline Asymmetric & $\begin{array}{l}-0.290 \\
(0.221)\end{array}$ & $\begin{array}{c}0.178^{* *} \\
(0.085)\end{array}$ & $\begin{array}{c}-0.794^{* * *} \\
(0.115)\end{array}$ & $\begin{array}{c}0.172^{* *} \\
(0.079)\end{array}$ & $\begin{array}{c}0.284^{* * *} \\
(0.059)\end{array}$ & $\begin{array}{l}-0.013 \\
(0.057)\end{array}$ & $\begin{array}{c}-0.498^{* * *} \\
(0.090)\end{array}$ & $\begin{array}{l}0.185^{* *} \\
(0.090)\end{array}$ \\
\hline Controls & YES & YES & YES & YES & YES & YES & YES & YES \\
\hline Constant & YES & YES & YES & YES & YES & YES & YES & YES \\
\hline Observations & 4,100 & 4,100 & 4,100 & 4,100 & 8,200 & 8,200 & 8,200 & 8,200 \\
\hline BIC & 4,572 & 4,469 & 5,195 & 5,171 & 9,758 & 9,741 & 44,217 & 44,161 \\
\hline
\end{tabular}

Table 4: Experiment 1 - Impacts of SDT predictions on observed behaviors with a dummy variable Loss Treatment.

Reading note: for each dependent variable, we present the causal effect of the corresponding predicted variable based on either optimal decision (odd numbers) or accuracy-maximizing (even numbers) strategies with control variables. Regressions are random-effect models logistic $(1,2,3,4,5,6)$ and Gaussian $(7,8)$. 


\begin{tabular}{|c|c|c|c|c|c|c|c|c|}
\hline & \multicolumn{8}{|c|}{ Dependent variable: } \\
\hline & \multicolumn{2}{|c|}{ Hit } & \multicolumn{2}{|c|}{ False Alarm } & \multicolumn{2}{|c|}{ Success } & \multicolumn{2}{|c|}{ Payoff } \\
\hline & $(1)$ & $(2)$ & $(3)$ & $(4)$ & $(5)$ & $(6)$ & $(7)$ & $(8)$ \\
\hline Loss Treatment & $\begin{array}{c}0.050 \\
(0.091)\end{array}$ & $\begin{array}{l}-0.019 \\
(0.093)\end{array}$ & $\begin{array}{c}0.015 \\
(0.083)\end{array}$ & $\begin{array}{c}0.019 \\
(0.083)\end{array}$ & $\begin{array}{l}-0.013 \\
(0.060)\end{array}$ & $\begin{array}{l}-0.020 \\
(0.060)\end{array}$ & $\begin{array}{l}-0.189 \\
(0.191)\end{array}$ & $\begin{array}{l}-0.124 \\
(0.190)\end{array}$ \\
\hline Hit Optimal & $\begin{array}{c}1.314^{* *} \\
(0.653)\end{array}$ & & & & & & & \\
\hline Hit Accuracy & & $\begin{array}{c}5.478^{* * *} \\
(0.479)\end{array}$ & & & & & & \\
\hline False Alarm Optimal & & & $\begin{array}{c}2.286^{* * *} \\
(0.199)\end{array}$ & & & & & \\
\hline False Alarm Accuracy & & & & $\begin{array}{c}5.374^{* * *} \\
(0.417)\end{array}$ & & & & \\
\hline Success Optimal & & & & & $\begin{array}{c}4.962^{* * *} \\
(0.212)\end{array}$ & & & \\
\hline Success Accuracy & & & & & & $\begin{array}{c}5.219^{* * *} \\
(0.217)\end{array}$ & & \\
\hline Point Optimal & & & & & & & $\begin{array}{c}0.986^{* * *} \\
(0.010)\end{array}$ & \\
\hline Point Accuracy & & & & & & & & $\begin{array}{c}0.993^{* * *} \\
(0.010)\end{array}$ \\
\hline Asymmetric & $\begin{array}{l}-0.303 \\
(0.224)\end{array}$ & $\begin{array}{l}0.190^{* *} \\
(0.091)\end{array}$ & $\begin{array}{c}-0.773^{* * *} \\
(0.120)\end{array}$ & $\begin{array}{c}0.172^{* *} \\
(0.084)\end{array}$ & $\begin{array}{c}0.288^{* * *} \\
(0.062)\end{array}$ & $\begin{array}{l}-0.006 \\
(0.060)\end{array}$ & $\begin{array}{c}-0.430^{* * *} \\
(0.114)\end{array}$ & $\begin{array}{c}0.226^{* *} \\
(0.110)\end{array}$ \\
\hline Constant & $\begin{array}{c}0.195 \\
(0.453)\end{array}$ & $\begin{array}{c}-2.701^{* * *} \\
(0.336)\end{array}$ & $\begin{array}{c}-1.340^{* * *} \\
(0.109)\end{array}$ & $\begin{array}{c}-2.344^{* * *} \\
(0.160)\end{array}$ & $\begin{array}{c}-2.586^{* * *} \\
(0.149)\end{array}$ & $\begin{array}{c}-2.756^{* * *} \\
(0.152)\end{array}$ & $\begin{array}{c}0.036 \\
(0.100)\end{array}$ & $\begin{array}{c}-0.0002 \\
(0.093)\end{array}$ \\
\hline Observations & 4,100 & 4,100 & 4,100 & 4,100 & 8,200 & 8,200 & 8,200 & 8,200 \\
\hline $\mathrm{BIC}$ & 4,507 & 4,407 & 5,134 & 5,112 & 9,767 & 9,750 & 44,133 & 44,062 \\
\hline
\end{tabular}

Table 5: Experiment 1 - Impacts of SDT predictions on observed behaviors with controls.

Reading note: for each dependent variable, we present the causal effect of the corresponding predicted variable based on either optimal decision (odd numbers) or accuracy-maximizing (even numbers) strategies with control variables. Regressions are random-effect models logistic $(1,2,3,4,5,6)$ and Gaussian $(7,8)$. 


\begin{tabular}{|c|c|c|c|c|c|c|c|c|}
\hline & \multicolumn{8}{|c|}{ Dependent variable: } \\
\hline & \multicolumn{2}{|c|}{ Hit } & \multicolumn{2}{|c|}{ False Alarm } & \multicolumn{2}{|c|}{ Success } & \multicolumn{2}{|c|}{ Payoff } \\
\hline & $(1)$ & $(2)$ & (3) & (4) & (5) & (6) & (7) & $(8)$ \\
\hline Hit CRRA & $\begin{array}{l}1.001^{* *} \\
(0.460)\end{array}$ & $\begin{array}{l}1.018^{* *} \\
(0.459)\end{array}$ & & & & & & \\
\hline False Alarm CRRA & & & $\begin{array}{c}1.560^{* * *} \\
(0.177)\end{array}$ & $\begin{array}{c}1.590^{* * *} \\
(0.180)\end{array}$ & & & & \\
\hline Success CRRA & & & & & $\begin{array}{c}4.719^{* * *} \\
(0.212)\end{array}$ & $\begin{array}{c}4.581^{* * *} \\
(0.240)\end{array}$ & & \\
\hline Point CRRA & & & & & & & $\begin{array}{c}0.991^{* * *} \\
(0.005)\end{array}$ & $\begin{array}{c}0.991^{* * *} \\
(0.005)\end{array}$ \\
\hline Asymmetric & $\begin{array}{l}-0.164 \\
(0.157)\end{array}$ & $\begin{array}{l}-0.169 \\
(0.157)\end{array}$ & $\begin{array}{c}-0.435^{* * *} \\
(0.107)\end{array}$ & $\begin{array}{c}-0.448^{* * *} \\
(0.108)\end{array}$ & $\begin{array}{c}0.283^{* * *} \\
(0.059)\end{array}$ & $\begin{array}{c}0.273^{* * *} \\
(0.059)\end{array}$ & $\begin{array}{c}-0.422^{* * *} \\
(0.091)\end{array}$ & $\begin{array}{c}-0.421^{* * *} \\
(0.090)\end{array}$ \\
\hline Controls & NO & YES & NO & YES & NO & YES & NO & YES \\
\hline Constant & YES & YES & YES & YES & YES & YES & YES & YES \\
\hline Observations & 4,100 & 4,100 & 4,100 & 4,100 & 8,200 & 8,200 & 8,200 & 8,200 \\
\hline $\mathrm{BIC}$ & 4,499 & 4,571 & 5,167 & 5,241 & 9,825 & 9,915 & 44,138 & 44,231 \\
\hline
\end{tabular}

Table 6: Experiment 1 - Impacts of utility-maximizing predictions on observed behaviors.

Reading note: for each dependent variable, we present the causal effect of the corresponding utilitymaximizing predicted variables with (even numbers) and without control variables (odd numbers). Regressions estimate random-effect models logistic $(1,2,3,4,5,6)$ and Gaussian $(7,8)$.

\begin{tabular}{|c|c|c|c|}
\hline & \multicolumn{3}{|c|}{ Dependent variable: } \\
\hline & $\begin{array}{l}\text { Hit } \\
(1) \\
\end{array}$ & $\begin{array}{c}\text { False Alarm } \\
(2)\end{array}$ & $\begin{array}{c}\text { Success } \\
(3) \\
\end{array}$ \\
\hline Predicted Hit & $\begin{array}{c}6.034^{* * *} \\
(0.565)\end{array}$ & & \\
\hline Predicted False Alarm & & $\begin{array}{c}4.035^{* * *} \\
(0.480)\end{array}$ & \\
\hline Predicted Success & & & $\begin{array}{c}4.852^{* * *} \\
(0.308)\end{array}$ \\
\hline Flat Treatment & $\begin{array}{c}0.055 \\
(0.101)\end{array}$ & $\begin{array}{c}0.047 \\
(0.094)\end{array}$ & $\begin{array}{c}0.001 \\
(0.068)\end{array}$ \\
\hline Controls & YES & YES & YES \\
\hline Constant & YES & YES & YES \\
\hline Observations & 2,150 & 2,150 & 4,300 \\
\hline BIC Flat & 1,338 & 1,430 & 2,750 \\
\hline BIC Incentive & 1,210 & 1,367 & 2,565 \\
\hline
\end{tabular}

Table 7: Experiment 2 - Impacts of SDT predictions on observed behaviors with controls.

Reading note: for each dependent variable, we present the causal effect of the corresponding predicted variable based on the accuracy-maximizing strategy with control variables. Regressions estimate logistic random-effect models. AIC correspond to regressions clustered per treatment. 


\section{Elicitation of attitudes toward risk, ambiguity and losses}

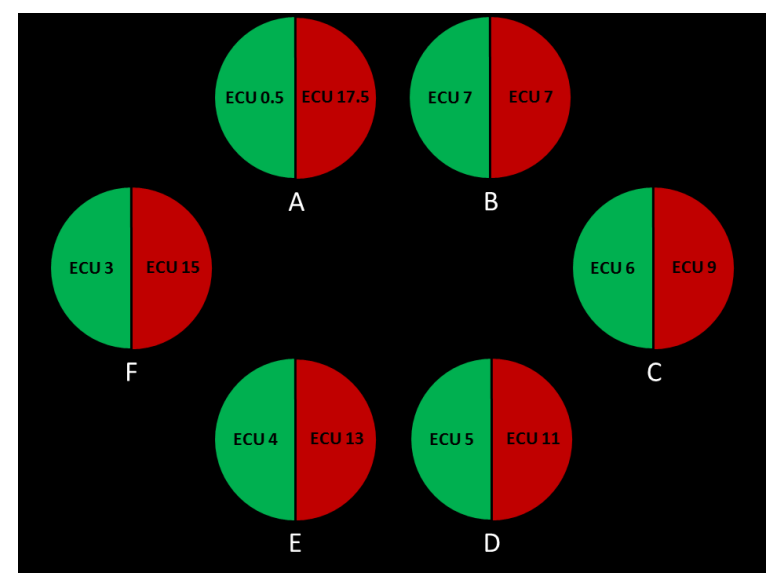

a-Decision 1 (gain, risk)

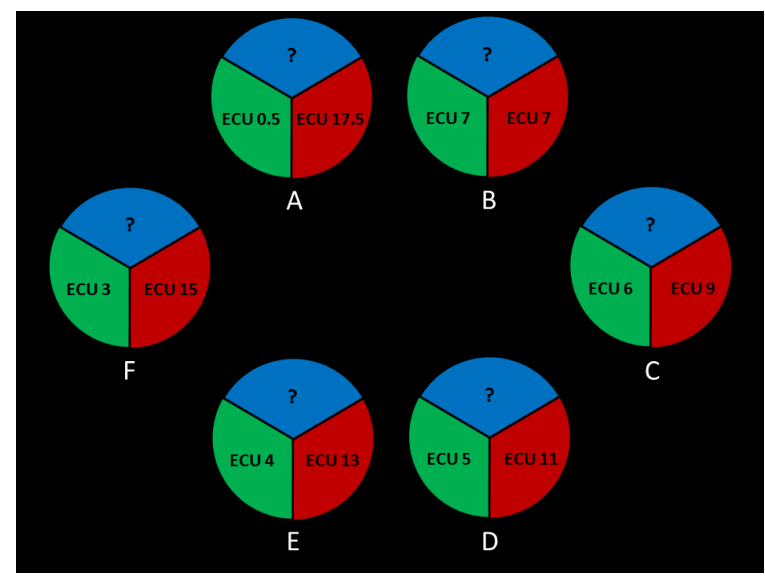

$c$ - Decision 3 (gain, ambiguity)

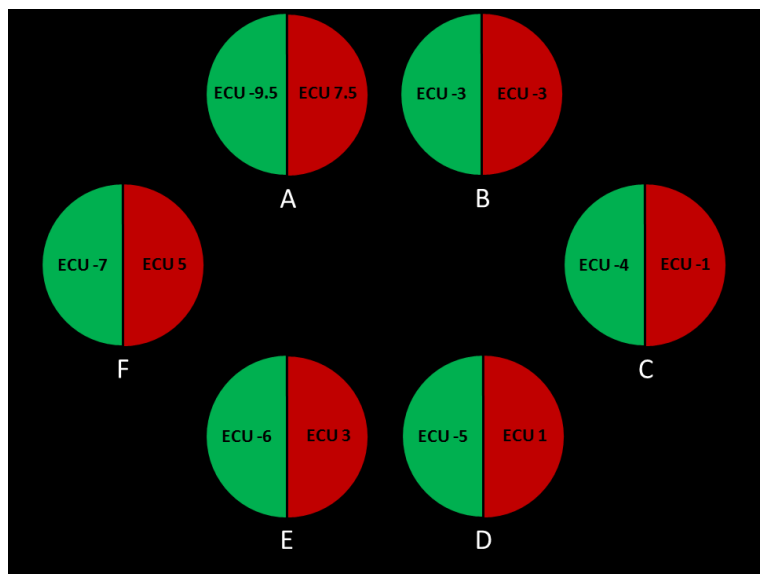

b- Decision 2 (loss, risk)

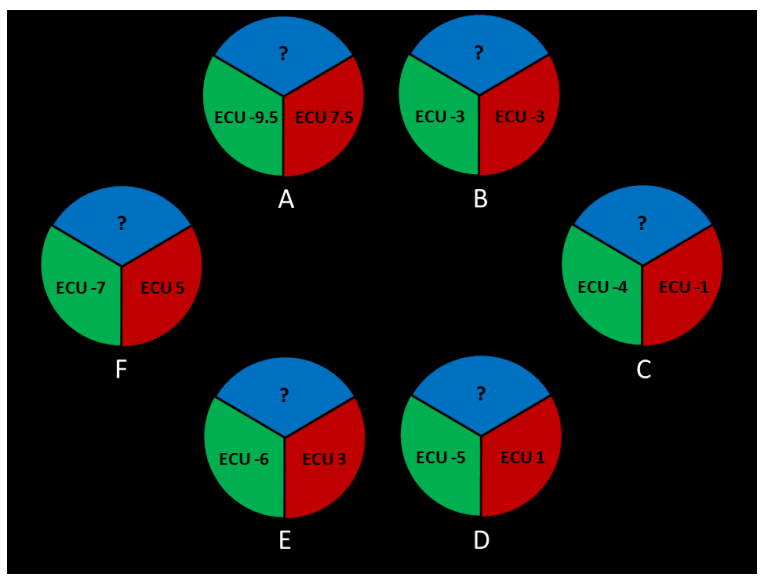

d-Decision 4 (loss, ambiguity)

Figure 1: Lottery-based decisions used to elicit attitudes toward risk, ambiguity and losses.

Reading note: Each circle represents a lottery. Lotteries' earnings are displayed within circles. Under risk, circles are divided in two equal shares as each outcome is equally likely. The uncertainty is graphically depicted by a "?" displayed on part of the circle to express the fact that the true probability is unknown. 


\section{Estimation of the utility-maximizing criterion us- ing standard or conservative methodologies}

\section{D.1 CRRA parameters estimation}

CRRA parameter under gain $\left(\gamma_{G}\right)$ - The elicitation of $\gamma_{G}$ is based on the mechanism from Eckel and Grossman (2008) (Decision 1). A parameter interval is associated with each lottery. The upper (respectively lower) bound of the parameter interval associated with a lottery is the parameter implying indifference between this lottery and the next lottery (respectively the previous one).

CRRA parameter under loss $\left(\gamma_{L}\right)$ - As Decision 2 involves both loss lotteries and mixed lotteries, we are unable to produce a direct estimation of $\gamma_{L}$ based on our elicitation task. We thus need to rely on previous research to estimate this parameter.

\section{D.2 Standard methodology}

Our approximation of $\beta_{U}^{*}$ is based on two assumptions. In the gain domain, following Reynaud and Couture (2012), we measure $\gamma_{G}$ as the centroides of each interval. ${ }^{1}$ In the loss domain, we assume than the diminishing sensitivity is equivalent to the one in gain, i.e. $\gamma_{G}=\gamma_{L}{ }^{2}$ We classify 31 subjects as risk averse in gain and risk seeker in loss, while 10 subjects exhibit the opposite pattern. ${ }^{3}$

Using these assumptions, we obtained that Hypothesis 1.1 and Hypothesis 1.3 were robust regarding risk attitude. While these assumptions were necessary to produce parameters estimations that have, in our view, the best likelihood of describing the true risk attitudes of subjects, it is important to assess if our results on utility-maximization are robust to changes in hypotheses. In a conservative approach we thus use assumptions that challenge the most our results and prove that they are still valid.

\section{D.3 Conservative methodology}

Hypothesis 1.1 is verified for the utility-maximizing criterion if subjects' criteria are lower than the utility-maximizing criteria. Hypothesis 1.3 is verified if subjects' criteria are

\footnotetext{
${ }^{1}$ For decisions $\mathrm{B}$ and $\mathrm{A}$, the corresponding parameter intervals are half-bounded. We take the closest integer value from the existing bound that is included in the interval: 4 for $] 3.45 ; \infty[$ and -1 for $]-\infty ; 0[$

${ }^{2}$ This reflection effect was empirically found by Tversky and Kahneman (1992). But evidence of the whole literature are more mitigated (cf. Note 1 in Wakker et al. (2007) for extensive references on the question).

${ }^{3}$ Note that we may overestimate the number of risk averse subjects in the loss domain as only 2 subjects took the lottery B in Decision 2 which can be seen as a risk averse behavior under loss.
} 
closer to the accuracy-maximizing criteria than to the utility-maximizing decision criteria. For higher estimated values of the utility-maximizing criteria, it is more difficult to conclude in favor of Hypothesis 1.1 and Hypothesis 1.3. We thus use the assumptions leading to the highest values of the utility-maximizing criteria, referred as conservative utility-maximizing criterion $\left(\beta_{U}^{c}\right)$, to assess the robustness of previous results.

Assumptions - Concerning risk parameters in the gain domain, we select the CRRA parameter within each parameter interval giving the highest value of $\beta_{c}^{*}$. As the utilitymaximizing decision criterion increases with the level of risk aversion $\left(\gamma_{G}\right)$, we use the upper bound each interval.

Individuals are generally risk seeking when confronted to losses (Fishburn and Kochenberger, 1979; Kahneman and Tversky, 1979). By including this risk seeking attitude in the CRRA utility function, we would obtained that utility-maximizing criteria are lower than optimal criteria in the loss domain. We relax this assumption by assuming that subjects are risk neutral in the loss domain $\left(\gamma_{L}=1\right)$. Utility-maximizing criterion are thus considered equal to optimal criterion for the loss treatment.

Estimation - The estimated $\beta_{U}^{c}$ have a mean of $0.627(s . d .=0.251)$ for the Low Gain Treatment and a mean of $0.438(s . d .=0.128)$ for the High Gain Treatment. By definition conservative utility-maximizing criteria are equal to the optimal criterion for the Symmetric Treatment and the Loss Treatment (respectively 1 and $\frac{1}{3}$ ).

Result: Hypothesis 1.1 is also supported for the conservative utility-maximizing decision criterion - SDT predictions at a subject-treatment level highlight that the observed success rate is $5.5 \%$ higher than the utility-maximizing success rate $(p-$ value $<0.001)$ for asymmetric treatments. It implies a payoff decrease of $10.2 \%$ ( $p$-value $<0.001)$. SDT predictions at a decision level reveal that conservative utility-maximizing predictions also lead to overestimate the hit rate, the false alarm rate and the payoffs while underestimating the success rate (SI Table 8).

Result: Hypothesis 1.3 is also supported for the conservative utility-maximizing decision criterion - Deviations from accuracy maximization are lower than deviations from conservative utility maximization both in term of success rate and payoffs (p-values: success $<0.001$ and payoff $=0.012$ ). 


\begin{tabular}{|c|c|c|c|c|c|c|c|c|}
\hline & \multicolumn{8}{|c|}{ Dependent variable: } \\
\hline & \multicolumn{2}{|c|}{ Hit } & \multicolumn{2}{|c|}{ False Alarm } & \multicolumn{2}{|c|}{ Success } & \multicolumn{2}{|c|}{ Payoff } \\
\hline & (1) & (2) & $(3)$ & $(4)$ & $(5)$ & $(6)$ & $(7)$ & $(8)$ \\
\hline Hit CRRA & $\begin{array}{l}0.698^{*} \\
(0.412)\end{array}$ & $\begin{array}{l}0.721^{*} \\
(0.411)\end{array}$ & & & & & & \\
\hline False Alarm CRRA & & & $\begin{array}{c}1.773^{* * *} \\
(0.178)\end{array}$ & $\begin{array}{c}1.804^{* * *} \\
(0.180)\end{array}$ & & & & \\
\hline Success CRRA & & & & & $\begin{array}{c}4.857^{* * * *} \\
(0.207)\end{array}$ & $\begin{array}{c}4.802^{* * *} \\
(0.236)\end{array}$ & & \\
\hline Payoff CRRA & & & & & & & $\begin{array}{c}0.995^{* * *} \\
(0.005)\end{array}$ & $\begin{array}{c}0.995^{* * *} \\
(0.005)\end{array}$ \\
\hline Asymmetric & $\begin{array}{l}-0.064 \\
(0.139)\end{array}$ & $\begin{array}{l}-0.070 \\
(0.138)\end{array}$ & $\begin{array}{c}-0.426^{* * *} \\
(0.101)\end{array}$ & $\begin{array}{c}-0.436^{* * *} \\
(0.101)\end{array}$ & $\begin{array}{c}0.209^{* * * *} \\
(0.058)\end{array}$ & $\begin{array}{c}0.206^{* * *} \\
(0.058)\end{array}$ & $\begin{array}{c}-0.423^{* * *} \\
(0.091)\end{array}$ & $\begin{array}{c}-0.423^{* * *} \\
(0.091)\end{array}$ \\
\hline Controls & NO & YES & NO & YES & NO & YES & NO & YES \\
\hline Constant & YES & YES & YES & YES & YES & YES & YES & YES \\
\hline Observations & 4,100 & 4,100 & 4,100 & 4,100 & 8,200 & 8,200 & 8,200 & 8,200 \\
\hline $\mathrm{BIC}$ & 4,500 & 4,573 & 5,151 & 5,225 & 9,765 & 9,858 & 44,134 & 44,227 \\
\hline
\end{tabular}

Table 8: Experiment 1 - Impacts of utility-maximizing predictions on observed behaviors.

Reading note: for each dependent variable, we present the causal effect of the corresponding utilitymaximizing predicted variables with (even numbers) and without control variables (odd numbers). Regressions estimate random-effect models logistic $(1,2,3,4,5,6)$ and Gaussian $(7,8)$.

\section{E Experimental instructions}

\section{E.1 Experiment 1}

\section{Task 1}

\section{General information:}

- Four sets of lotteries will be presented to you. For each set, you will have to choose one lottery out of six possibilities.

- Each lottery is composed of two different payoffs.

- When you select a lottery, you earn either the payoff on the left or on the right.

\section{Proceeding:}

- First lottery: No losses possible (no endowment), $50 \%$ of chance for the two different payoffs.

- Second lottery: Losses possible (endowment), $50 \%$ of chance for the two different payoffs.

- Third lottery: No losses possible (no endowment), between $30 \%$ and $70 \%$ of chance for the two different payoffs.

- Fourth lottery: Losses possible (endowment), between $30 \%$ and $70 \%$ of chance for the two different payoffs. 


\section{Task 2}

\section{General information:}

- Determine if both circles contain either the same or a different number of dots.

- If you think that they contain the same number of dots, press the key $\downarrow$ on your keyboard.

- If you think that they contain a different number of dots, press the key $\uparrow$ on your keyboard.

For each decision, four outcomes are possible:

\begin{tabular}{cc|c|c} 
& & \multicolumn{2}{|c}{ Correct answer } \\
& Different & Same \\
\hline Decision & $\begin{array}{c}\text { Different } \\
\text { Same }\end{array}$ & $\begin{array}{l}\text { Success when different } \\
\text { Failure when different }\end{array}$ & Failure when similar \\
& Success when similar
\end{tabular}

- To each possible outcome is associated a certain number of points.

- Your objective is to maximize the number of points earned.

Feedback:

- After each decision you will know if you were right or wrong and the number of points earned for this decision.

- Every 10 decisions, you will have:

- An aggregated accuracy feedback: the percentage of correct answer during the last 10 decisions.

- An aggregated point feedback: how close you are from the highest number of points compared to the lowest number of points accumulated during the last 10 decisions.

\section{Steps:}

- First training period without points.

- Second training period with points.

- Paid part: 4 blocks of 50 decisions. Points pattern are fixed within each block. 


\section{Earnings}

Additionally to the AUD5 of show-up fee, you will receive:

\section{First part:}

- One of the chosen lottery will be randomly selected. You will be paid according to its result.

- Payoffs are in ECU.

- The conversion rate between ECU and AUD is:

$$
2 E C U=A U D 1
$$

\section{Second part:}

- Five decisions randomly selected in each block.

- Your payment is the sum of all points accumulated during the $4^{*} 5$ selected decisions.

- Losses will occur but they will be more than compensated by your gains even in the worst case scenario.

- The conversion rate between points and AUD is:

$$
8 \text { points }=A U D 1
$$

\section{E.2 Experiment 2}

\section{Task}

\section{General information:}

- Determine if both circles contain either the same or a different number of dots.

- If you think that they contain the same number of dots, press the key $\downarrow$ on your keyboard.

- If you think that they contain a different number of dots, press the key $\uparrow$ on your keyboard.

For each decision, four outcomes are possible:

\begin{tabular}{cc|c|c} 
& & \multicolumn{2}{|c}{ Correct answer } \\
& Different & Same \\
\hline Decision & Different & Success & Failure \\
& Same & Failure & Success
\end{tabular}

- To each possible outcome is associated a certain number of points. 
- Your objective is to maximize the number of points earned.

\section{Feedback:}

- After each decision you will know if you were right or wrong and the number of points earned for this decision.

- Every 10 decisions, you will have:

- An aggregated accuracy feedback: the percentage of correct answer during the last 10 decisions.

- An aggregated point feedback: how close you were from the highest number of points during the last 10 decisions.

\section{Steps:}

- First training period without point.

- Second training period with points.

- Paid part: 2 blocks of 50 decisions. Points patterns are fixed within each block.

\section{Earnings}

Additionally to the AUD5 of show-up fee, you will receive:

- Five decisions randomly selected in each block.

- Your variable payment is the sum of all points accumulated during the $2^{*} 5$ selected decisions.

- The conversion rate between points and AUD is:

$$
8 \text { points }=A U D 1
$$




\section{References}

Eckel, C. C. and Grossman, P. J. (2008). Forecasting risk attitudes: An experimental study using actual and forecast gamble choices. Journal of Economic Behavior 6 Organization, 68(1):1-17.

Fishburn, P. C. and Kochenberger, G. A. (1979). Two-piece von neumann-morgenstern utility functions. Decision Sciences, 10(4):503-518.

Kahneman, D. and Tversky, A. (1979). Prospect theory: An analysis of decision under risk. Econometrica, 47(2):263-292.

Reynaud, A. and Couture, S. (2012). Stability of risk preference measures: results from a field experiment on french farmers. Theory and decision, 73(2):203-221.

Tversky, A. and Kahneman, D. (1992). Advances in prospect theory: Cumulative representation of uncertainty. Journal of Risk and uncertainty, 5(4):297-323.

Wakker, P. P., Köbberling, V., and Schwieren, C. (2007). Prospect-theory's diminishing sensitivity versus economics' intrinsic utility of money: How the introduction of the euro can be used to disentangle the two empirically. Theory and Decision, 63(3):205-231. 